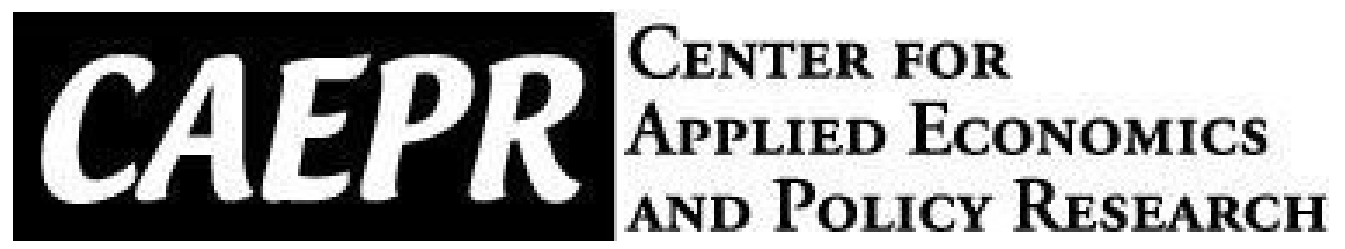

\author{
CAEPR \\ Working Paper \\ \#2018-003
}

Fiscal Commitment and Sovereign Default Risk

\author{
Siming Liu \\ Indiana University \\ Hewei Shen \\ Indiana University
}

April 19, 2018

This paper can be downloaded without charge from the Social Science Research Network electronic library at https://papers.ssrn.com/abstract_id=3165726

The Center for Applied Economics and Policy Research resides in the Department of Economics at Indiana University Bloomington. CAEPR can be found on the Internet at: http://www.indiana.edu/ caepr. CAEPR can be reached via email at caepr@indiana.edu or via phone at 812-855-4050.

(C)2018 by Siming Liu and Hewei Shen. All rights reserved. Short sections of text, not to exceed two paragraphs, may be quoted without explicit permission provided that full credit, including (C) notice, is given to the source. 


\title{
Fiscal Commitment and Sovereign Default Risk*
}

\author{
Siming $\mathrm{Liu}^{\dagger}$ \\ Hewei Shen $\ddagger$ \\ Indiana University \\ Indiana University
}

April 19, 2018

\begin{abstract}
This paper studies the effects of fiscal policy commitment in countries that suffer sovereign default risk. Since a government does not incorporate the effect of their taxation decisions on past bond prices, a time-inconsistency problem arises, resulting in too many defaults and too few fiscal adjustments. We show that a fiscal commitment device can mitigate the government's default incentives and improve their borrowing opportunities. Moreover, instead of committing to a single tax rate, introducing a commitment device that depends on economic conditions can further reduce default risk while preserving the contingency of a pro-cyclical fiscal policy.

Keywords: Sovereign default risk; Pro-cyclical fiscal policy; Time-inconsistency; Fiscal commitment; Fiscal austerity

JEL Classification: E62, F34, F41
\end{abstract}

\footnotetext{
${ }^{*}$ We are indebted to Grey Gordon and Juan Carlos Hatchondo for their thoughtful comments. We thank seminar and conference participants at 2016 Fall Midwest Macroeconomics Meeting and the 11th Washington University in St. Louis Graduate Student Conference. All errors are our own.

${ }^{\dagger}$ Corresponding Author. Department of Economics, Indiana University, Bloomington. Email: simliu@indiana.edu

${ }^{\ddagger}$ Department of Economics, Indiana University, Bloomington. Email: hewei.shen@outlook.com
} 


\section{Introduction}

During the recent European debt crisis, the Greek government was criticized for its irresponsible public spending and undisciplined fiscal policies. With an average ratio of government deficit to GDP at $7.63 \%$ between 2000 and 2009, the ratio of public debt to GDP in Greece climbed over $130 \%$ in 2009 . As the global financial crisis unfolded, international investors began to worry about Greece's ability to meet its debt obligations. As a result, the risk premium on Greek bonds rose steadily, and the Greek government was on the brink of default. To prevent an outright default, Eurozone leaders and the IMF offered several financial assistance packages to Greece under the condition of fiscal austerity. Consequently, the Greek parliament passed a list of fiscal austerity reforms, and promised to reduce the deficit in the next few years ${ }^{1}$.

Figure 1 shows the announcement dates of the 14 austerity reforms that the Greek government has implemented since 2009. As shown in the figure, the Greek government has been introducing new fiscal austerity plans continuously between 2010 and 2017. Despite these efforts, there remains a heated debate on the interaction between fiscal austerity and sovereign debt crises. Why did Eurozone leaders and the IMF require the Greek government to perform fiscal austerity reforms during a sovereign debt crisis and why did the Greek government has an incentive to accept them? How does such a promise of tougher fiscal policies in the future affect the government's ability to repay outstanding debt? This paper addresses these questions by analyzing the interconnection between fiscal commitment and sovereign default risk in a quantitative model.

In order to investigate the interaction between fiscal commitment and sovereign default, we build a sovereign default model with optimal taxation and government spending. The model economy is populated by four types of agents - households, firms, government and foreign lenders. Households enjoy leisure, private and public consumption, and supply labor to the firms for wage income. Firms are subject to productivity shocks and use labor to produce consumption goods. A benevolent government levies a distortionary labor tax and issues one-period non-contingent bonds to foreign investors to finance its spending on public goods. In the model, the bond repayment is not enforceable and the government may decide to default on its debt. Foreign lenders are risk-neutral and charge a risk premium on the bond to account for the default risk they face when lending to the government. As in Cuadra et al. (2010), the model predicts a pro-cyclical fiscal policy, that is, the government levies a high tax rate in economic downturns when the risk premium on the government bond rises due to the increased default risk.

In this environment, we show that a time-inconsistency problem arises when the discretionary government optimally chooses the tax rates after making default decisions. During economic downturns, the government can choose either to levy a high tax rate in order to repay its debt or to default on its debt to avoid an excessive distortion of the economy from the high tax rate. Since the current government makes default-taxation decision solely on its debt balance and productivity realization, it disregards the effect of its decision on the past bond price. Consequently, the government chooses to default too frequently and is reluctant to make fiscal adjustments. The excessive

\footnotetext{
${ }^{1}$ See Nelson et al. (2011) for an overview of Greece's debt crisis.
} 


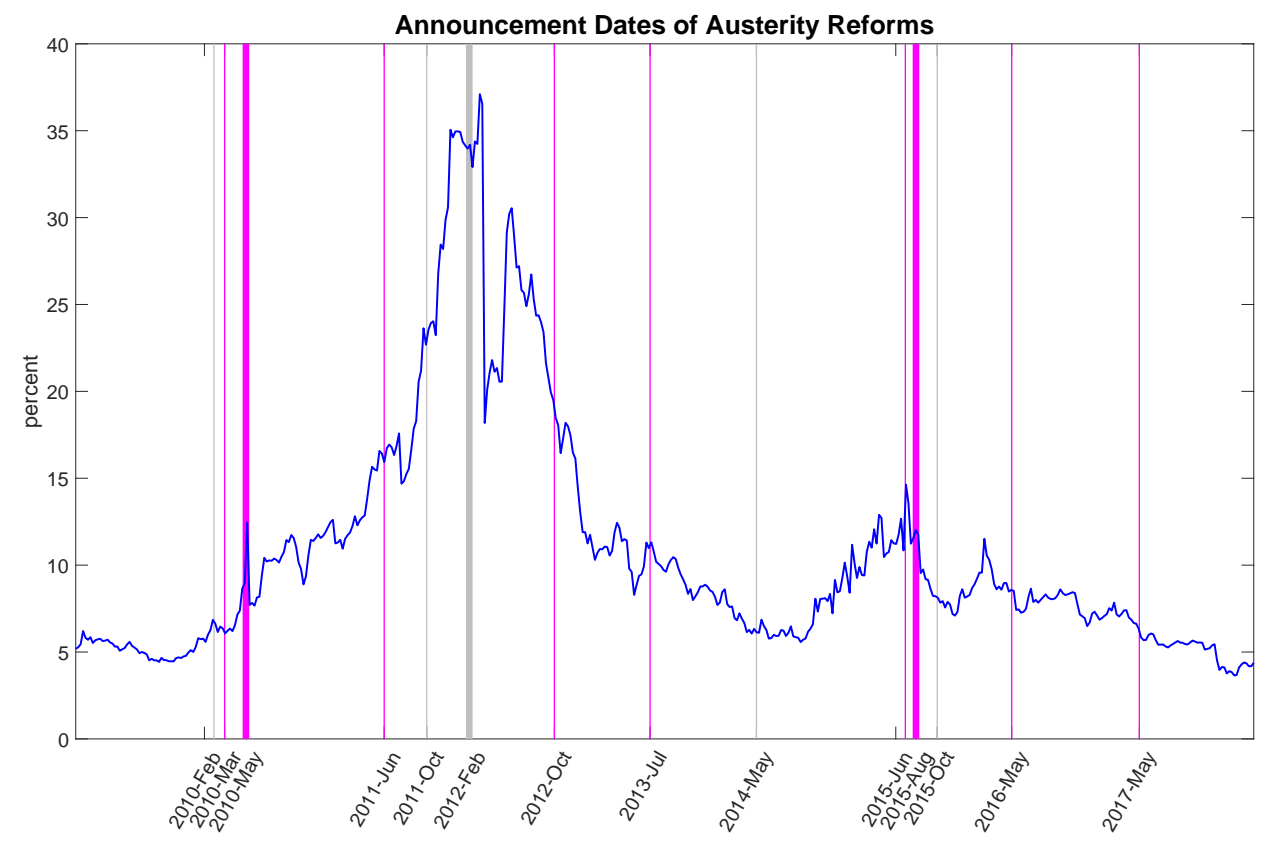

Note: This figure displays the announcement dates of the 14 austerity reforms that the Greek government implemented since 2009. The pink lines refer to the austerity packages including tax reforms. The thick lines are the three austerity packages used to ensure the installments of three major bailout loans the Greek government received from the EU, ECB and IMF, which are also called Economic Adjustment Programme. The blue line shows the yield of the Greek 10-year government bond.

Figure 1: The Announcement of the 14 Austerity Reforms in Greece

default incidence is priced by foreign creditors and limits the government's ability to borrow.

This time-inconsistency problem creates a role for a fiscal commitment device to alleviate default risk. In this paper, we use the model to assess the value of the commitment implied by the continuous fiscal austerity plans that the Greek government proposed, as shown in figure 1. Specifically, we consider two types of fiscal commitment: a non-contingent tax commitment and a contingent tax commitment ${ }^{2}$. Under the non-contingent tax commitment, the government sets a single tax rate at the time of the bond issuance. In the next period, the preset tax rate is implemented, regardless of the government's default decision and shock realizations. Under the contingent tax commitment, the government is more flexible and is able to customize the schedule of tax policy to future economic fundamentals. More specifically, the government commits to a tax plan that is contingent on the productivity realizations of the next period ${ }^{3}$.

\footnotetext{
${ }^{2}$ In this paper, we assume the commitment devices are always available and we evaluate the effect of imposing fiscal commitment on the indebted economies. Gonçalves and Guimaraes (2015) argues that in practice, a third party institution like IMF can perfectly carry out this role and has incentive to enforce the debtor countries to implement the committed fiscal adjustment.

${ }^{3}$ The contingent commitment captures that sometimes the fiscal austerity packages are contracted to be contingent on economic conditions and are flexible to change over time. One example is the creation of a contingency spending cuts mechanism introduced as a part of the third bailout package for Greece in 2016. On the other hand, the noncontingent commitment captures a more stringent or more rigid austerity plan that applies to the most of other cases.
} 
Under a non-contingent tax commitment, we find that the government tends to commit to a high tax rate for the next period when the current debt burden is high or productivity is low. The high committed tax rate suppresses the government's incentive to default in the following period, reducing the risk premium that the current government has to pay when issuing bonds, and creating more borrowing opportunities. However, since a government who can freely set the tax rate conducts a pro-cyclical fiscal policy, the fiscal rigidity implied by the non-contingent commitment limits the government's ability to adjust the tax rate. This prevents the optimal allocation of resources between private and public consumption, resulting in an ex post welfare loss. It is shown that the ex ante benefit of the tax commitment in reducing default risk is partly offset by its ex post cost when the commitment device is simple and non-contingent. On the other hand, the noncontingency cost of making a commitment is substantially reduced if we allow the government to tailor a schedule of committed tax rates based on the upcoming state of productivity ${ }^{4}$. Under this contingent commitment, we find that the government only commits to raising the tax rate in bad states where commitment is most valuable. By preserving the pro-cycliality of fiscal policy, the contingent commitment device is more effective at reducing default risk than the non-contingent commitment and enables the government to sustain a even higher level of debt.

We calibrate our model to the Greek economy and use it as a laboratory to evaluate the austerity commitment made by its government during the recent years. The commitment devices described above are similar to the fiscal austerity reforms enacted by the Greek government in exchange for the financial aid packages from the international institutions. As a part of these fiscal austerity reforms, the Greek government drastically increased the VAT rates, income tax rates, and sales tax rates on various goods ${ }^{5}$. Under the conditions of the financial aid packages, the Greek government must maintain these austerity plans over a specified period. First, we find both commitment devices help the government reduce default incentives and increase debt sustainability. The larger debt sustainability is transmitted into a more favorable borrowing condition. In the limiting distribution, however, the government becomes more indebted and the better borrowing condition does not necessarily translate into a lower default probability or a smaller risk premium on bond. Last, we find that the contingent tax commitment is more effective in mitigating default risk than the noncontingent tax commitment because it helps the government reap the benefit from commitment without incurring the cost of fiscal rigidity. In our simulations, the contingent tax commitment allows the government to implement austerity less frequently and to enjoy a higher bond price, thereby inducing more capital inflows.

With mitigated default risks and a higher level of borrowing, the tax commitments generate sizable welfare gains. Under the non-contingent tax commitment, the government's average wel-

\footnotetext{
${ }^{4}$ Usually, the cost of fiscal rigidity may come from either legislative process or implementation lag. This paper focuses on the benefit of making fiscal commitment for increasing financial credibility.

${ }^{5}$ As ECB president Mario Dragh stated in the press conference of May 2, 2013, a fiscal austerity based on the current expenditure cut should be less contractionary than increasing tax rates. Unfortunately, many of the fiscal austerity measures were implemented in an emergency situation and raising taxes was the simplest route. See https://www.ecb.europa.eu/press/pressconf/2013/html/is130502.en.html. In this paper, we focus on analyzing the effect of austerity commitment when fiscal reforms are based on tax adjustments.
} 
fare improves by $0.26 \%$ of permanent consumption based on the limiting distribution of the nocommitment economy. Due to the smaller ex post cost, the contingent commitment creates a even larger welfare gain of $0.96 \%$. Additionally, the conditional welfare gain from the commitment policies is higher as the economy approaches the default threshold.

In practice, most of the austerity packages were designed to be temporary and the agreements were frequently updated according to the changes in economic conditions or renegotiation between the government and external parties. Such a short-term arrangement raises a question about the credibility of austerity measures and leads to the concern about the government's incentive to deviate from its commitment. We show that imposing a relatively small cost would be enough to prevent the government's deviations from the committed austerity tax rate. Moreover, the cost necessary to enforce the contingent tax commitment is much smaller than cost for the noncontingent commitment.

Finally, we use the model to examine the Greek debt crisis event and analyze whether the commitment of fiscal austerity since 2010 reduced the path of risk premium on government bonds. First, we map the model with a discretionary fiscal policy to the Greek economy and estimate a sequence of productivity shocks that leads to the path of the output and government spending dynamics as in the data. Next, we feed-in the extracted shocks to the models with the tax commitments and compare the model-predicted paths of risk premium. The numerical results show that, compared to the economy with discretionary fiscal policy, the austerity commitments indeed reduce the risk premiums during the recent debt crisis. In addition, the government with the contingent tax commitment implements the austerity less frequently than the government with the non-contingent tax commitment.

Our findings highlight the importance of fiscal commitment in reducing default risk and also rationalize the ECB's continuous efforts to enforce the austerity reforms on the European debtor countries under debt crises. As mentioned by Mario Draghi in a press conference, "a key issue of fiscal consolidation is credibility; and with a very credible fiscal consolidation framework, the countries could be rewarded with much lower interest rates on their sovereign bonds." The results in this paper emphasize that the commitment of fiscal austerity is indeed important for establishing the credibility. The greater credibility benefits the home country at the time of debt issuance and alleviates the severity of crises. Additionally, policy recommendations should acknowledge that economic condition may change over time and imposing a simple austerity plan could be suboptimal due to the ex post non-contingency cost. This echos the popular view that austerity has strong distortionary effect in the short-run and may drive the economy into deeper recessions. The comparison between the two types of tax commitments demonstrated in this paper indicates that a superior austerity plan should be flexible enough to accommodate changes in future economic conditions.

Related Literature This paper builds on the literature that studies fiscal policy under the soverign default framework proposed by Eaton and Gersovitz (1981) and Arellano (2008). The related examples are Cuadra et al. (2010), Hatchondo et al. (2015), Gonçalves and Guimaraes 
(2015), and Arellano and Bai (2017). Cuadra et al. (2010) shows that in a model with endogenous fiscal policy and sovereign default, debt is less useful for the government to smooth consumption fluctuations and taxes are optimally pro-cyclical. This is also true for our baseline economy without fiscal commitment. Building on this result, we further find that the government's fiscal policy with tax commitment is more pro-cyclical than without commitment. Arellano and Bai (2017) studies how a fiscal constraint makes default more likely: the default option helps free up resources available to the government to finance public consumption when tax rates cannot change. While their paper evaluates the effect of the tax rigidity on sovereign default risk, our paper allows the government to choose (committed) tax rates optimally and explores the benefit of making fiscal commitment. Fiscal rigidities are still present in our model, which may either come ex post from the non-contingent taxation or ex ante from the one-period implementation lag.

The paper most closely related to ours is Gonçalves and Guimaraes (2015). They use a theoretical model to show that a time-inconsistency problem arises when the government chooses the tax rate each period after debt has been issued. A tighter fiscal policy can reduce the amount of borrowing and lessen default risk, but the government cannot commit to do so. They also design a commitment device for fiscal adjustment that could be enforced by a third party institution, like the IMF, who have the proper incentives to evaluate the state of nature for the indebted economy. Our paper differs from theirs in several dimensions. First, since their model has longterm bonds, the value of fiscal commitment comes from the fact that higher taxation reduces the future refinancing needs of the government and mitigates the debt dilution risk. Instead, we work in a short-term bond environment and the commitment channel in our paper is due to the different effects of tax rate on repayment and default values. More aggressive taxation increases the relative benefit of repaying the debt over defaulting on it. Second, we use a quantitative model to evaluate the equilibrium effects of fiscal commitment when debtor countries conduct austerity reforms and compute the countries' welfare improvements after imposing the fiscal commitment. Third, we compare different commitment structures and explicitly discuss the trade-off between the ex ante smaller default incentive and the ex post larger non-contingency cost. Furthermore, we show that commitment devices should be made contingent on changes in economic conditions.

Our paper is also related to the literature examining the effect of fiscal rules in the sovereign default environment. Bi (2012) studies how the fiscal policy determines debt limits that arise endogenously from dynamic Laffer curves. She finds that long-run fiscal austerity measures can alleviate the default risk premium. However, the paper uses a closed economy model, and default is determined by an ad hoc rule that depends on level of debt and other states of the economy. Hatchondo et al. (2015) studies the effect of introducing fiscal rules on the governments' default problem. They show that an optimal debt-brake (or spread-brake) rule can successfully reduce default risk by restricting government budget balance and mitigating the debt dilution problem. Moreover, a spread brake is more robust to model parametrization than a debt brake. In their paper, the time-inconsistency problem stems from the conflict that the government does not consider the effect of its future borrowing decisions on the current bond price, and the problem is only present in the model with long-term bond. In contrast, the conflict in our model lies between the current debt 
issuance and the future discretionary fiscal policy so that the problem appears even in a short-term bond environment.

The rest of the paper is organized as follows. Section 2 develops a two-period model that allows us to present the time-inconsistency problem and to explain how fiscal commitment improves welfare. Section 3 builds a quantitative model to examine the government's optimal fiscal austerity. Section 4 calibrates the model to the Greek economy and shows how the austerity policy with tax commitment reduces the government's default premium and increases its debt sustainability. We also compare two types of commitment structures and show their corresponding welfare benefits. Section 5 concludes.

\section{A Two-Period Model}

This section presents a two-period model and discusses the interaction between fiscal commitment and sovereign default.

\subsection{The Model with Discretionary Fiscal Policy}

Initially, we assume that the government cannot make a fiscal commitment when issuing sovereign bonds (we refer to this as discretionary fiscal policy). There are two periods, $t=1,2$, and one good. A small open economy is populated by a representative household who enjoys only public consumption in the first period and a combination of private and public consumption in the second period. The representative household has no income in the first period and has a random amount of endowment income in the second period. We assume that income in the second period follows a uniform distribution, $y_{2} \sim U\left[y_{\min }, y_{\max }\right]$. There is a benevolent government in the economy who borrows from the international financial market, collects taxes from the representative household, and provides public consumption.

In the first period, the government issues a one-period non-contingent bond to foreign investors to finance the provision of public consumption. The bond repayment is not enforceable and the government may default on its debt after observing the income realizations in the second period. If it defaults, the debt is written-off but the economy loses a fraction of its income. The government bond is priced by competitive risk-neutral investors who discount its future payment at a rate of 1. In the second period, after making the default decision, the government may levy a tax on the household's income to finance the debt repayment (if repaying) and the public consumption. Last, the household uses its after-tax income for the private consumption.

In the first period, the benevolent government makes the bond issuance decision to maximize the household's expected life-time utility,

$$
\frac{g_{1}^{1-\sigma}}{1-\sigma}+\beta \mathbb{E}_{y_{2}}\left[(1-\pi) \frac{c_{2}^{1-\sigma}}{1-\sigma}+\pi \frac{g_{2}^{1-\sigma}}{1-\sigma}\right]
$$

where $c$ and $g$ are the household's private and public consumption, respectively. Parameters $\beta, \sigma$, and $\pi$ are the household's discount factor, risk aversion, and utility weight of public consumption in 
the second period. Let $q\left(b_{2}\right)$ denote the bond price, which is determined by competitive risk-neutral investors,

$$
q\left(b_{2}\right)=\mathbb{E}_{y_{2}}\left(1-d\left(b_{2}, y_{2}\right)\right)
$$

$d\left(b_{2}, y_{2}\right)$ is an indicator function of the government's period 2 default decision and it depends on the debt balance $b_{2}$ and income realization $y_{2}$. The household's public consumption $\left(g_{1}\right)$ in the first period equals the proceeds from the bond issuance,

$$
g_{1}=q\left(b_{2}\right) b_{2}
$$

In the second period, if the government defaults, the economy loses a fraction of its income and the remaining income is given by $\phi y_{2}$, where $\phi \in(0,1)$. Therefore, the household's private $\left(c_{2}\right)$ and public $\left(g_{2}\right)$ consumption depend on the income realization $\left(y_{2}\right)$, the government's default decisions $(d)$, and the tax rate $(\tau)$,

$$
\begin{aligned}
& c_{2}\left(b_{2}, y_{2}\right)=\left[1-d\left(b_{2}, y_{2}\right)\right]\left(1-\tau\left(b_{2}, y_{2}\right)\right) y_{2}+d\left(b_{2}, y_{2}\right)\left(1-\tau\left(b_{2}, y_{2}\right)\right) \phi y_{2}, \\
& g_{2}\left(b_{2}, y_{2}\right)=\left[1-d\left(b_{2}, y_{2}\right)\right]\left[\tau\left(b_{2}, y_{2}\right) y_{2}-b_{2}\right]+d\left(b_{2}, y_{2}\right) \tau\left(b_{2}, y_{2}\right) \phi y_{2} .
\end{aligned}
$$

\subsection{Default Decision and Tax Rate under Discretionary Fiscal Policy}

In this section, we discuss the government's default decision and tax rate under the discretionary fiscal policy. In section 2.3, we assume that the government is able to commit to future tax rates when issuing the debt, and discuss the effect of introducing this tax commitment on the government's borrowing, default decision, and welfare.

Under the discretionary fiscal policy, the government chooses tax rates after making the default decision in the second period. Therefore, we solve the model backward and first characterize the government's conditional tax policy in the second period. The results are summarized in the following proposition.

Proposition 1. The government's conditional tax policy, given its default decision in the second period, is characterized by the following:

1. When the government defaults, the optimal tax rate is a constant, independent of the income realizations,

$$
\tau^{* D}\left(y_{2}\right)=\tau^{* D}
$$

2. The optimal tax rates under repayment are consistently higher than the tax rate under default, that is,

$$
\tau^{* R}\left(y_{2}, b_{2}\right)>\tau^{* D}
$$

for any $y_{2} \in\left[y_{\min }, y_{\max }\right]$ and $b_{2}>0$.

3. When the government repays its debt, the optimal tax rate increases with the level of the debt 
balance and decreases with the income realization,

$$
\frac{\partial \tau^{* R}\left(y_{2}, b_{2}\right)}{\partial b_{2}}>0, \quad \frac{\partial \tau^{* R}\left(y_{2}, b_{2}\right)}{\partial y_{2}}<0
$$

Proof. See Appendix A.1.

When defaulting, the government sets an optimal tax rate to finance public consumption ${ }^{6}$. However, when repaying its debt, the government not only needs to finance public consumption but also needs to generate enough resources to serve its debt. As a result, proposition 1 suggests that the government sets a higher tax rate when repaying than defaulting. On the other hand, if the debt balance is high or the income realization is low, the repaying government has to set a higher tax rate in order to generate enough tax revenue to sustain the debt. Therefore, proposition 1 states that the government conducts a pro-cyclical fiscal policy under repayment and the tax rate increases with the debt balance. In other words, the government wants to conduct an austerity policy at the state of high debt or low income.

Given the optimal tax policy, the government makes its default decision in the second period after observing the income realizations. Specifically, let $V^{2, R}\left(b_{2}, y_{2}\right)$ denote the value of repaying the debt and $\tau^{* R}\left(y_{2}, b_{2}\right)$ solves the following problem:

$$
\begin{aligned}
& V^{2, R}\left(b_{2}, y_{2}\right)=\max _{\tau \in[0,1]}\left\{(1-\pi) \frac{c_{2}^{1-\sigma}\left(b_{2}, y_{2}\right)}{1-\sigma}+\pi \frac{g_{2}^{1-\sigma}\left(b_{2}, y_{2}\right)}{1-\sigma}\right\}, \\
& \text { s.t. } c_{2}\left(b_{2}, y_{2}\right)=(1-\tau) y_{2}, \\
& g_{2}\left(b_{2}, y_{2}\right)=\tau y_{2}-b_{2} .
\end{aligned}
$$

Similarly, let $V^{2, D}\left(y_{2}\right)$ denote the value of default. $\tau^{* D}\left(y_{2}\right)$ solves the problem of,

$$
\begin{aligned}
& V^{2, D}\left(y_{2}\right)=\max _{\tau \in[0,1]}\left\{(1-\pi) \frac{c_{2}^{1-\sigma}\left(y_{2}\right)}{1-\sigma}+\pi \frac{g_{2}^{1-\sigma}\left(y_{2}\right)}{1-\sigma}\right\}, \\
& \text { s.t. } c_{2}\left(y_{2}\right)=(1-\tau) \phi y_{2}, \\
& g_{2}\left(y_{2}\right)=\tau \phi y_{2} .
\end{aligned}
$$

The government decides whether or not to default by comparing the repayment value to the default value,

$$
V^{2}\left(b_{2}, y_{2}\right)=\max _{d \in\{0,1\}}\left\{(1-d) V^{2, R}\left(b_{2}, y_{2}\right)+d V^{2, D}\left(y_{2}\right)\right\} .
$$

We assume that the government repays its debt when these two values equal to each other. Proposition 2 summarizes the government's default decision in the model without fiscal commitment,

Proposition 2. The government defaults in the second period when income realization is smaller than a threshold, $y_{2}<b_{2} /(1-\phi)$.

\footnotetext{
${ }^{6}$ From the first order condition of tax rate for the government's second period problem, the optimal consumption ratio between the private and the public sector is $c_{2} / g_{2}=((1-\pi) / \pi)^{-1 / \sigma}$.
} 
Proof. See Appendix A.2.

When the debt balance is high and the income realization is low, repaying the debt becomes very costly for the economy. As a result, the government chooses to default on its debt, which incurs an income loss. Given the government's decision in the second period, the bond price in the first period reflects the probability that the government will default and thus it is a decreasing function of the face value of the debt, $b_{2}$ :

$$
q\left(b_{2}\right)=\left\{\begin{array}{l}
0, \text { if } \frac{b_{2}}{1-\phi}>y_{\max } \\
1-\frac{1}{y_{\max }-y_{\min }}\left(\frac{b_{2}}{1-\phi}-y_{\min }\right), \text { if } y_{\min } \leq \frac{b_{2}}{1-\phi} \leq y_{\max } \\
1, \text { if } \frac{b_{2}}{1-\phi}<y_{\min }
\end{array}\right.
$$

Last, given the second period values and the bond price schedule, the government in the first period chooses a borrowing amount to maximize the household's lifetime utility:

$$
\begin{gathered}
V^{1}=\max _{b_{2}}\left\{\frac{g_{1}^{1-\sigma}}{1-\sigma}+\beta \mathbb{E}_{y_{2}} V^{2}\left(b_{2}, y_{2}\right)\right\} \\
\text { s.t. } \quad g_{1}=q\left(b_{2}\right) b_{2} .
\end{gathered}
$$

\subsection{Fiscal Commitment in the Two-Period Model}

In this section, we assume that the government is able to commit to a tax policy in the second period at the time of bond issuance in the first period. We consider two types of fiscal commitment. First, we assume that the government sets a single tax rate when it borrows. The government cannot change the preset tax rate in the second period regardless of the income realizations and its default decision. We refer it as "non-contingent tax commitment" since the government's tax plan does not vary with the exogenous state. Second, we assume that the government can commit to a schedule of tax rates that depends on the income realizations in the second period, and we explore the optimal state-contingent tax schedule made by the government. We refer this type of commitment as "contingent tax commitment". In this section, we discuss the effect of introducing these two commitment devices on the government's default decision, borrowing, and the welfare of the economy.

\subsubsection{Non-Contingent Tax Commitment}

With the non-contingent tax commitment, the government presets a tax rate at the same time of debt issuance in the first period. Similar to the model without fiscal commitment, we solve the model backward and first characterize the government's default decision in the second period. In the second period, the government only decides whether to default or not, taking the preset tax 
rate as given. Therefore, the value of repayment is,

$$
\begin{aligned}
V^{2, R}\left(b_{2}, y_{2}, \tau\right) & =(1-\pi) \frac{c_{2}^{1-\sigma}}{1-\sigma}+\pi \frac{g_{2}^{1-\sigma}}{1-\sigma}, \\
\text { s.t. } \quad c_{2} & =(1-\tau) y_{2}, \\
g_{2} & =\tau y_{2}-b_{2},
\end{aligned}
$$

and the value of default is,

$$
\begin{aligned}
V^{2, D}\left(y_{2}, \tau\right) & =(1-\pi) \frac{c_{2}^{1-\sigma}}{1-\sigma}+\pi \frac{g_{2}^{1-\sigma}}{1-\sigma}, \\
\text { s.t. } \quad c_{2} & =(1-\tau) \phi y_{2}, \\
g_{2} & =\tau \phi y_{2} .
\end{aligned}
$$

The government's default decision depends on the comparison between these two values,

$$
V^{2}\left(b_{2}, y_{2}, \tau\right)=\max _{d \in\{0,1\}}\left\{(1-d) V^{2, R}\left(b_{2}, y_{2}, \tau\right)+d V^{2, D}\left(y_{2}, \tau\right)\right\}
$$

Proposition 3 characterizes how the government's default decision depends on the committed tax rate.

Proposition 3. The government's default decision with the non-contingent tax commitment is described by:

1. Given the debt balance $b_{2}$ and committed tax rate $\tau$, there exists a threshold $\bar{y}_{2}\left(b_{2}, \tau\right)$ such that the government repays (defaults on) its debt when $y_{2} \geq(<) \bar{y}_{2}\left(b_{2}, \tau\right)$.

2. If $y_{\min }<\bar{y}_{2}\left(b_{2}, \tau\right)<y_{\max }$ holds, the default threshold decreases in the committed tax rate and increases in the debt balance,

$$
\frac{\partial \bar{y}_{2}\left(b_{2}, \tau\right)}{\partial \tau}<0, \quad \frac{\partial \bar{y}_{2}\left(b_{2}, \tau\right)}{\partial b_{2}}>0
$$

Proof. See Appendix A.3.

Since the income in the second period $y_{2}$ follows a uniform distribution, a lower default threshold $\bar{y}_{2}\left(b_{2}, \tau\right)$ means that the government is less likely to default. Therefore, proposition 2 states that a higher committed tax rate can reduce the probability of default in the second period. To see why this is true, note that the second period intra-temporal Euler equation when the government can freely set the tax rate is:

$$
\pi g_{2}\left(b_{2}, y_{2}\right)^{-\sigma}=(1-\pi) c_{2}\left(b_{2}, y_{2}\right)^{-\sigma}, \quad \forall y_{2}, b_{2}
$$

Equation (15) captures the optimal allocation of resources between private and public consumption, for both the repayment and the default problems. Any deviation from the optimal tax rate creates 
a welfare loss in the second period. Suppose the preset tax rate $\tau$ is high and the government defaults on its debt. In this case, the high tax rate provides too much public consumption and too little private consumption according the relationship in (15), thus yielding a lower value of default $V^{D}\left(y_{2}, \tau\right)$. Instead, if the government uses the greater amount of tax revenue to repay its debt, it can avoid the income loss from default and also provide a combination of private and public consumption that is closer to the relationship in equation (15). Hence, the drop in the value of repayment $V^{R}\left(b_{2}, y_{2}, \tau\right)$ is relatively small after $\tau$ increases (or it has a larger increase) ${ }^{7}$. Overall, the higher committed tax rate increases the relative benefit of repaying the debt over defaulting on it, and thus reducing the government's default incentive.

As the preset tax rate affects the government's default decision in the second period, the bond price depends on both the debt balance and the committed tax rate:

$$
q\left(b_{2}, \tau\right)=\left\{\begin{array}{l}
0, \quad \text { if } \bar{y}_{2}\left(b_{2}, \tau\right)>y_{\max } \\
1-\frac{\bar{y}_{2}\left(b_{2}, \tau\right)-y_{\min }}{y_{\max }-y_{\min }}, \text { if } y_{\min } \leq \bar{y}_{2}\left(b_{2}, \tau\right) \leq y_{\max } \\
1, \quad \text { if } \bar{y}_{2}\left(b_{2}, \tau\right)<y_{\min }
\end{array}\right.
$$

As shown in equation (16), a higher committed tax rate $\tau$ decreases the government's incentive to default in the second period and thus raises the bond price in the first period. Figure 2 shows the result in a numerical example ${ }^{8}$. The left panel shows the bond pricing schedules for different committed tax rates. First, the bond price decreases in the level of bond issuance since the the government is more likely to default in the second period when the debt balance is high. Second, the higher committed tax rate $\tau$ reduces the government's incentive to default, shifting the bond price toward the right.

In the first period, the government simultaneously chooses the bond issuance $b_{2}$ and the nextperiod tax rate $\tau$ to maximize the lifetime utility of the household,

$$
\begin{aligned}
& V^{1}=\max _{\left\{b_{2}, \tau\right\}}\left\{\frac{g_{1}^{1-\sigma}}{1-\sigma}+\beta \mathbb{E}_{y_{2}} V^{2}\left(y_{2}, b_{2}, \tau\right)\right\}, \\
& \text { s.t. } g_{1}=q\left(b_{2}, \tau\right) b_{2} .
\end{aligned}
$$

The Euler equation with respect to the tax rate is given by

$$
g_{1}^{-\sigma} b_{2} \frac{\partial q\left(b_{2}, \tau\right)}{\partial \tau}+\beta \frac{\partial \mathbb{E}_{y_{2}} V^{2}\left(y_{2}, b_{2}, \tau\right)}{\partial \tau}=0
$$

In equation (19), the term $\partial q\left(b_{2}, \tau\right) / \partial \tau$ reflects that the government's internalization of the effect of its tax commitment on the bond price in the first period. Specifically, the government understands

\footnotetext{
${ }^{7}$ The fact that the higher tax rate raises the value of repayment faster than the value of default (or decrease it by less) can be seen from proposition 1. Given the optimal tax rate under repayment is always higher than the optimal tax rate under default, we can see that with a higher preset tax rate, the government prefers repaying the debt over defaulting on it by more.

${ }^{8}$ In the numerical exercise of our two-period model, the parameter values are set as: $\sigma=2, \pi=0.185, \beta=1$, $\phi=0.64, y_{\min }=0.5$ and $y_{\max }=1.5$.
} 

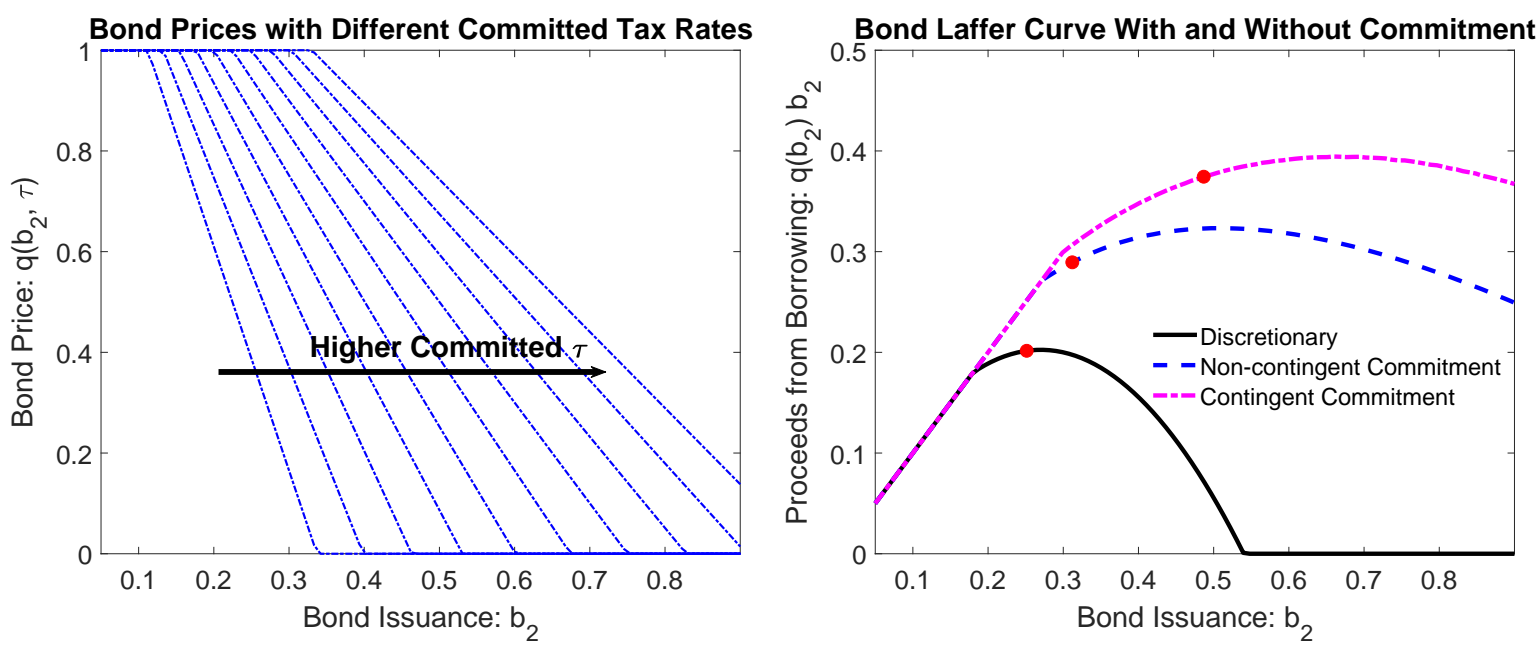

Note: The left panel shows the bond prices as functions of bond issuance with different values of committed tax rates. The right panel shows the bond Laffer curves under different types of fiscal commitment. For every value of bond issuance $b_{2}$, we assume that the government chooses the best corresponding tax commitment in the right panel. The red dots indicate the government's equilibrium choices of bond issuance.

Figure 2: Bond prices and Laffer curves with and without commitment

that it can issue the bond at a higher price if it commits to a tougher fiscal policy in the future. The right panel of figure 2 compares the bond Laffer curves faced by the government in period 1 and its optimal borrowing decisions. With the non-contingent tax commitment, the government earns a more favorable borrowing opportunity by mitigating its future default incentive and tends to borrow more than the case without commitment.

Next, we consider the welfare effect of the non-contingent fiscal commitment. In the second period, the default option provides the government an insurance against the low income realizations. By committing to a preset tax rate and reducing the government's incentive to default, the commitment diminishes this insurance benefit and reduces the household's second period welfare, $\mathbb{E}_{y_{2}} V^{2}\left(y_{2}, b_{2}, \tau\right)$. In addition, the non-contingency itself creates an ex post welfare loss by disallowing the government to set the tax rate to achieve the desired allocation between private and public consumption, as in equation (15). On the other hand, the fiscal commitment device lowers the probability of default, increasing the government's ability to borrow and to front-load consumption.

Figure 3 illustrates the benefit and cost for the fiscal commitment measure. It displays the household's lifetime utilities and the expected values in the second period at each level of bond issuance $b_{2}$. The red dots indicate the government's equilibrium borrowing decisions, which maximize the household's lifetime utility. In all cases, a higher bond issuance increases the debt balance in the second period and makes the continuing values decline. On the other hand, the lifetime utilities as functions of bond issuance are hump-shaped as the government's borrowing ability is limited by the debt Laffer curves. Consistent with the intuition above, the right panel of figure 3 shows that the 

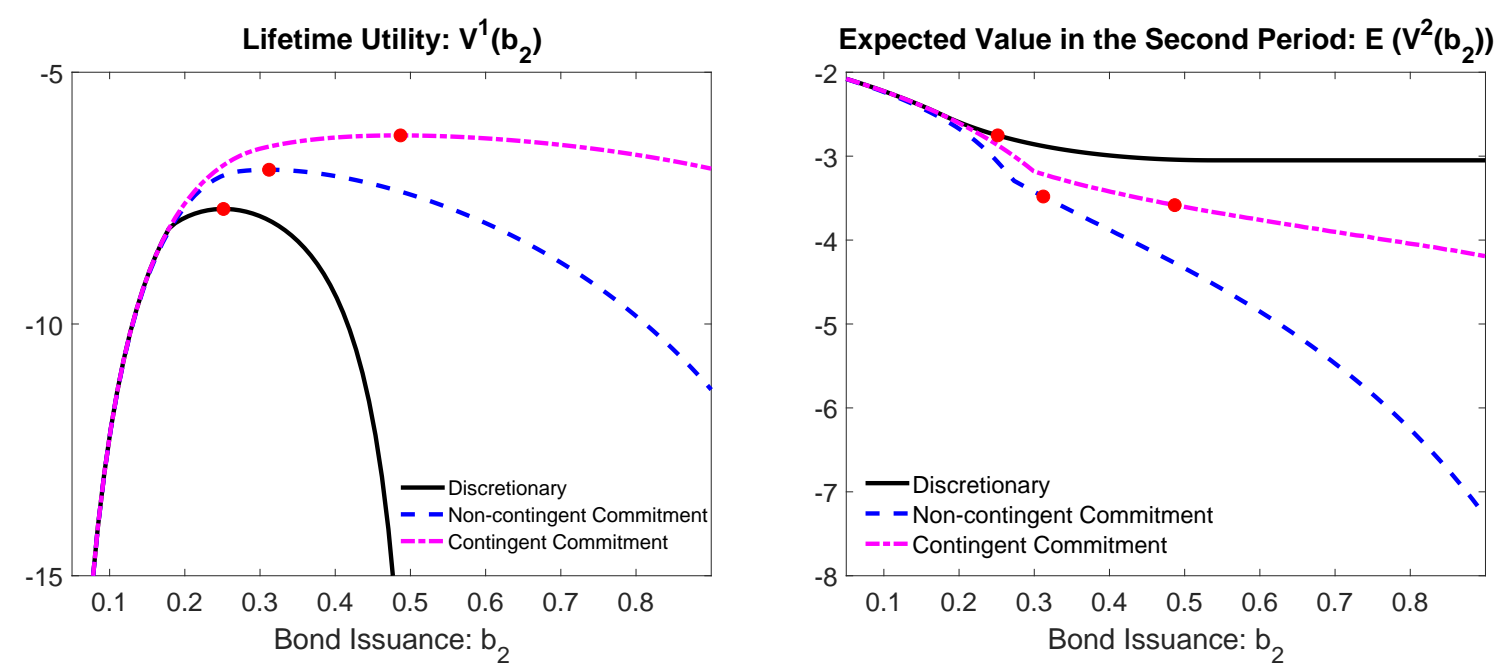

Note: The red dots indicate the government's choices of bond issuance in equilibrium under different types of fiscal commitment.

Figure 3: Lifetime utility and the expected value in the second period

tax commitment lowers the continuing value at each level of debt. However, due to the effect on bond price, the commitment device enhances the government's ability to borrow and increases the first period welfare. As in the left panel, the benefit of commitment dominates the cost, resulting in consistently higher life-time utilities under non-contingent tax commitment than under discretionary fiscal policy. In equilibrium, the government also borrows more under the commitment, generating a welfare improvement.

\subsubsection{Contingent Tax Commitment}

In the previous section, we demonstrated that the non-contingent tax commitment improves economic welfare by suppressing the government's incentive to default and improving its borrowing condition in the first period. However, the non-contingency restricts the government's ability to adjust tax rates based on economic conditions and creates an ex post welfare loss ${ }^{9}$. In this section, we assume that the government can commit to a schedule of tax rates that is contingent on income realizations. We show that the contingent commitment policy has a greater ability to reduce default risk and improve borrowing opportunities, and thus it further increases the welfare ${ }^{10}$.

Under the contingent tax commitment, the government chooses a functional of tax schedule $\tau\left(y_{2}\right)$

\footnotetext{
${ }^{9}$ As discussed in proposition 1 , the discretionary tax policy is pro-cyclical.

${ }^{10}$ We have also shown the optimal contingent commitment tax perform pro-cyclically, similar to the discretionary policy that is only ex post optimal. As discussed in Cuadra et al. (2010), pro-cyclical fiscal policy can effectively hedge against sovereign borrowing risk for emerging economies.
} 


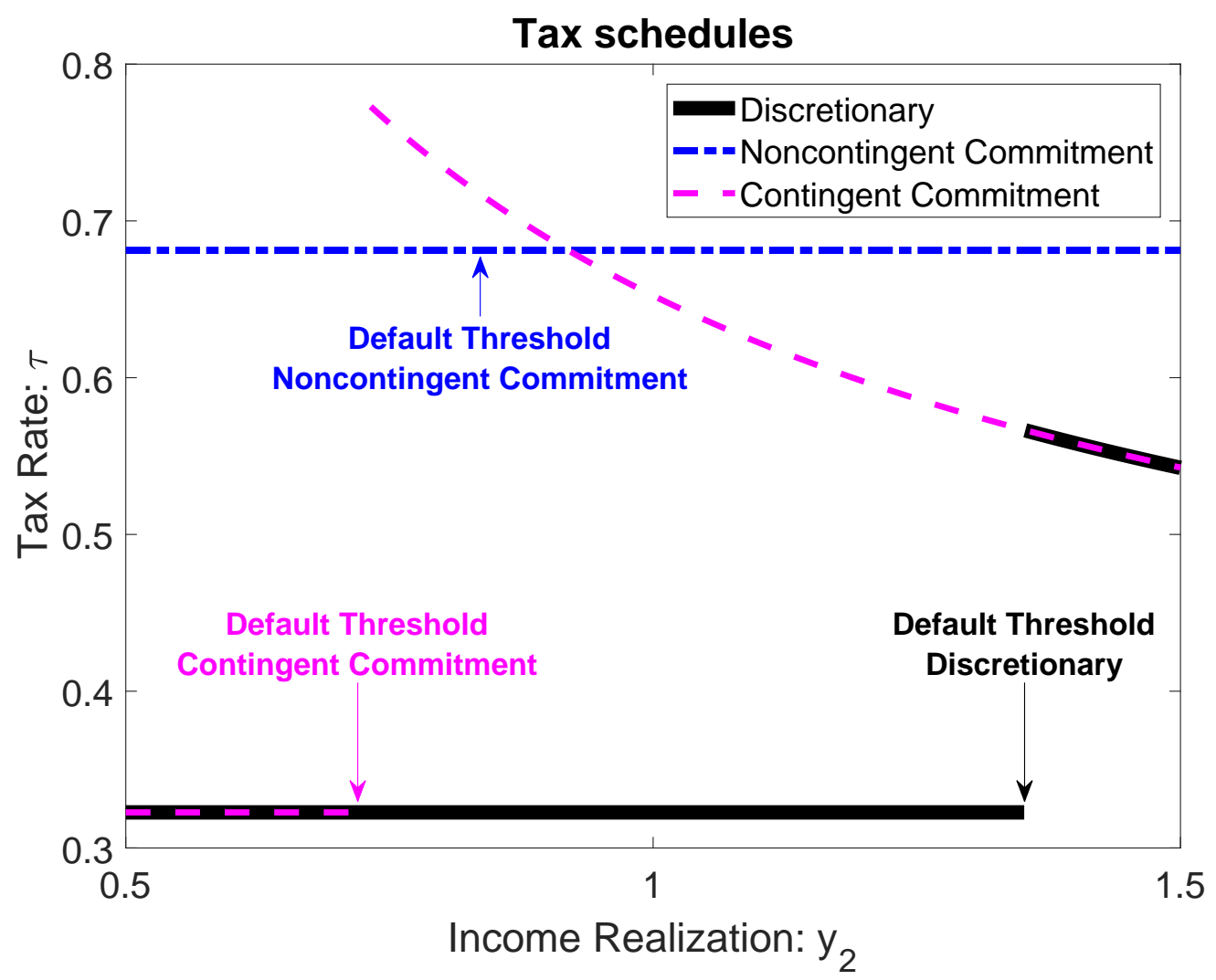

Note: We assume that the governments make same amount of bond issuance (equilibrium bond issuance under the contingent tax commitment) when comparing these three cases.

Figure 4: The Tax Rate Schedules under the Discretionary Fiscal Policy and Tax Commitments

in the first period to maximize the household's lifetime utility ${ }^{11}$,

$$
\begin{aligned}
& V^{1}=\max _{\left\{b_{2}, \tau\left(y_{2}\right)\right\}}\left\{\frac{g_{1}^{1-\sigma}}{1-\sigma}+\beta \mathbb{E}_{y_{2}} V^{2}\left(y_{2}, b_{2}, \tau\left(y_{2}\right)\right)\right\}, \\
& \text { s.t. } g_{1}=q\left(b_{2}, \tau\left(y_{2}\right)\right) b_{2} .
\end{aligned}
$$

In the second period, the problem is similar to the case of non-contingent tax commitment, except that now the government implements the contingent tax plan set in the first period. On one hand, when setting the tax schedule, the government incorporates how the future default probability affects the bond price and can use the commitment to suppress default incentives. On the other hand, because the government can tailor a full menu of tax rates based on the future incomes, it is optimal to choose the tax policy that a discretionary government would implement, which induces the optimal allocation between private and public consumption in the second period, as in equation (15).

This intuition is confirmed by figure 4, which compares the tax rate schedules under the contin-

\footnotetext{
${ }^{11}$ The implemented tax rate in the second period depends on income realizations.
} 


\begin{tabular}{|c|c|c|c|}
\hline & $\begin{array}{c}\text { Discretionary } \\
\text { Policy }\end{array}$ & $\begin{array}{c}\text { Non-Contingent } \\
\text { Commitment }\end{array}$ & $\begin{array}{l}\text { Contingent } \\
\text { Commitment }\end{array}$ \\
\hline Lifetime utility & -7.71 & -6.93 & -6.25 \\
\hline Expected second-period value & -2.75 & -3.48 & -3.58 \\
\hline Debt issuance & 0.25 & 0.31 & 0.49 \\
\hline Probability of default & $19.8 \%$ & $7.3 \%$ & $23.2 \%$ \\
\hline $\begin{array}{l}\text { Non-contingency cost: } \\
\qquad \operatorname{cov}\left(\frac{u_{g}\left(c_{2}, g_{2}\right)}{u_{c}\left(c_{2}, g_{2}\right)}, y_{2}\right)\end{array}$ & 0 & 0.29 & 0 \\
\hline
\end{tabular}

Table 1: The Numerical Results of the Two-period Model

gent tax commitment and discretionary fiscal policy ${ }^{12}$. There are several common features between these policy functions. The government defaults when the income realization is lower than a certain threshold and the tax rates under repayment are always higher than the ones under default. In addition, fiscal policies are always pro-cyclical at repayment states so that the tax rate decreases when the income realization increases. Note that the default threshold under contingent tax commitment is much lower than the default threshold under discretionary policy, which implies the government has a smaller default probability with the commitment device. By maintaining the relatively high tax rates at intermediate income states, the government successfully reduces its default incentives. However, for the extremely low income states, the government optimally switches to the defaulting tax rate to prevent the costly high taxation. Such a state-contingent tax plan allows the government to manipulate the default probability more effectively, and at the same time, minimize ex post the cost of commitment. The latter point is evident in that, at high income states, the tax policy under contingent commitment exactly mimics the discretionary policy.

Compared to the non-contingent tax commitment, the contingent commitment allows the government to reduce its default probability more effectively. Figure 2 shows that the policy further expands the bond Laffer curve to the right. Since the cost of commitment is also smaller, as shown in the right panel of figure 3, the expected second-period value for the contingent commitment is lower than that of discretionary policy, but higher than that of non-contingent tax. Compared to the latter case, due to both the smaller ex post cost and the improved bond price schedule, the government borrows even more and the contingent commitment generates a higher lifetime utility (the left panel of figure 3).

Table 1 summarizes these results for all three cases in our numerical example. Both commitment devices enhance the government's ability to borrow by reducing the default risk at each level of borrowing. The higher indebtedness under fiscal commitment exacerbates the expected value in the second period. However, the stronger ability to borrow combined with more lenient bond prices enables the government to generate higher utility in the first period. As a result, both commitment measures create welfare improvements over the case of discretionary policy. In addition, because the contingent tax commitment helps the government reap the benefits from both the pro-cyclical

\footnotetext{
${ }^{12}$ The figure also plots the tax rate under the non-contingent tax commitment for comparison.
} 
fiscal policy and the commitment, the government borrows the most heavily ( 0.49 vs. 0.25 for the discretionary policy) without inducing much more default probability $(23.2 \%$ vs. $19.8 \%$ for the discretionary policy). As a result, the case of contingent commitment attains the larger welfare gain.

The last row in table 1 provides a measure indicating the state-contingency of tax policies. A smaller value indicates the stronger ability to customize the tax rates based on shock realizations (or a smaller non-contingency cost). Compared to discretionary fiscal policy, the non-contingent commitment incurs a larger cost due to the ex post tax rigidity. However, the contingent tax commitment enables the government to preserve a pro-cyclical fiscal policy, and thus retains the ability to provide the optimal consumption ratios at each state of nature.

\section{$3 \quad$ Full Model}

This section builds an infinite horizon model with fiscal commitment. In the following section, we quantitatively study the effect of committing to an austerity tax rate and evaluate the corresponding welfare results. We consider a small open economy with four types of agents: a representative firm demands labor and produces the consumption good; a continuum of households supply labor and enjoy private and public consumption; a benevolent government sets fiscal policy and borrows in the international market; and foreign creditors buy bond securities issued by the government. Similar to the two-period model, the government's problem is differentiated by its ability to make fiscal commitment and is separated into three cases. We first describe the model structure and then discuss the different fiscal commitments. For simplicity, we assume that the government can only set the tax rate to one of the two values: $\tau^{L}$ and $\tau^{H}$. Denote the space of tax rates as $\mathcal{T}=\left\{\tau^{L}, \tau^{H}\right\}$, where $\tau^{L}$ represents the tax rate in normal times (normal tax rate) and $\tau^{H}$ indicates a higher tax rate under fiscal austerity (austerity tax rate) ${ }^{13}$.

Households enjoy private and public consumption, and derive disutility from labor. The households' life-time utility is given by,

$$
\mathbb{E}_{0} \sum_{t=0}^{\infty} \beta^{t} u\left(c_{t}, l_{t}, g_{t}\right)
$$

where $\beta$ is the discount factor. Households face a static problem in each period since they do not have access to the financial market. Taking policies $\left\{g_{t}, \tau_{t}\right\}$ as given, they supply labor, pay the wage income tax, and buy consumption goods to maximize their per-period utility,

$$
\begin{array}{ll} 
& \max _{c_{t}, l_{t}} u\left(c_{t}, l_{t}, g_{t}\right), \\
\text { s.t. } & c_{t}=\left(1-\tau_{t}\right) w_{t} l_{t} .
\end{array}
$$

\footnotetext{
${ }^{13}$ The discussion about how to choose $\tau^{L}$ and $\tau^{H}$ together with other model parameters is in section 4.1
} 
where $w_{t}$ is the wage rate. The first order condition of the households' problem is,

$$
-\frac{u_{l}\left(c_{t}, l_{t}\right)}{u_{c}\left(c_{t}, l_{t}\right)}=\left(1-\tau_{t}\right) w_{t}
$$

Equation (25) implies that the labor income tax puts a wedge between the wage rate and the marginal rate of substitution of consumption and labor and thus distorts the households' labor decisions. The representative firm hires labor to produce the consumption good using a linear production function: $y_{t}=z_{t} l_{t}$. The logarithm of firm's productivity $z_{t}$ follows an $\operatorname{AR}(1)$ process:

$$
\log \left(z_{t}\right)=\left(1-\rho_{z}\right) \mu_{z}+\rho_{z} \log \left(z_{t-1}\right)+\epsilon_{t}
$$

where the i.i.d. shock $\epsilon_{t}$ follows $\mathbb{N}\left(0, \sigma_{z}^{2}\right)$ and $\mu_{z}=-0.5 \sigma_{z}^{2}$. Parameter $\rho_{z}$ is the persistence of TFP. The representative firm maximizes its profit in each period and the first order condition yields the wage,

$$
w_{t}=z_{t}
$$

In each period, the government chooses public consumption $\left(g_{t}\right)$, levies a proportional tax on the labor income $\left(\tau_{t}\right)$, and borrows in the international bond market $\left(b_{t+1}\right)$. The government cannot promise to repay its debt and may choose to default $\left(d_{t}\right)$ on its debt balance due. If the government defaults $\left(d_{t}=1\right)$, it is temporarily excluded from the international market and a productivity loss is incurred during the exclusion. At the beginning of each period during the exclusion, the economy has a chance to reenter the financial market with a probability $\xi$. After reentering, all debts are written off and the government can borrow again. In the model, the government's policy set can be expressed as a quadruple: $\Xi_{t}=\left\{d_{t}, b_{t+1}, g_{t}, \tau_{t}\right\}$. Given the government's policy, we can define the private sector's competitive equilibrium as follows,

Definition 1. The competitive equilibrium is defined as a set of allocations $\left\{c_{t}, l_{t}, y_{t}\right\}_{t=0}^{\infty}$ and prices $\left\{w_{t}\right\}_{t=0}^{\infty}$ such that: (1) Taking the government policies $\left\{\Xi_{t}\right\}_{t=0}^{\infty}$ as given, households and the representative firm solve their optimization problem; (2) Goods market clear in each period: $c_{t}+g_{t}=y_{t}=z_{t} l_{t}$.

Using equation (24), (25) and (27), the competitive equilibrium is characterized by the optimality condition and budget constraint:

$$
\begin{aligned}
& -\frac{u_{l}\left(c_{t}^{*}, l_{t}^{*}\right)}{u_{c}\left(c_{t}^{*}, l_{t}^{*}\right)}=\left(1-\tau_{t}\right) z_{t}, \\
& c_{t}^{*}=\left(1-\tau_{t}\right) z_{t} l_{t}^{*},
\end{aligned}
$$

where the superscript '* ${ }^{*}$ denotes the household and the firm's equilibrium choices, taking the government's policies as given. Next, we discuss the government's problem with and without fiscal commitment. The government's problem is expressed in a recursive formulation, where we denote $x$ as a current period variable and $x^{\prime}$ as a variable in the next period. 


\subsection{Case 1: Discretionary Tax Policy}

In case 1 , the government cannot make any fiscal commitment so it decides the current period tax rate at the same time of issuing new debt. Therefore, we refer this case as "discretionary tax policy". The state variables in this case are debt balance $b$ and productivity $z$ and we let $S^{(1)}=(b, z)$ denote the aggregate state of the economy. At the beginning of each period, a government with good credit standing chooses whether to default on its debt by comparing the value associated with repaying its debt and remaining in the credit market $V^{R}(b, z)$, with the value associated with defaulting and going into temporary autarky $V^{D}(z)$. The problem is expressed as:

$$
V(b, z)=\max _{d \in\{0,1\}}\left\{(1-d) V^{R}(b, z)+d V^{D}(z)\right\} .
$$

where $d$ indicates the government's default decision.

If the government chooses to repay, it remains in good credit standing and can issue new debt. Taking the private equilibrium and future public policies as given, the government chooses a contemporaneous tax rate, public consumption, and debt issuance. Specifically, the repaying government solves the following problem:

$$
V^{R}(b, z)=\max _{\tau \in \mathcal{T}, g, b^{\prime}}\left\{u\left(c^{*}, l^{*}, g\right)+\beta \mathbb{E} V\left(b^{\prime}, z^{\prime}\right)\right\}
$$

subject to the budget constraint,

$$
g+b=\tau z l^{*}+q\left(b^{\prime}, z\right) b^{\prime},
$$

where the consumption $c^{*}$ and labor $l^{*}$ are determined by the optimality conditions (28) and (29). $q\left(b^{\prime}, z\right)$ is the price of the bond that pays one unit of consumption good in the next period and it is priced by the competitive risk-neutral foreign creditors, which will be discussed below.

If the government chooses to default on its debt, it is temporarily banned from the international market. The firms' productivity drops to $0<h(z) \leq z$ during this exclusion. In the next period, the government can re-enter the debt market with a probability $\xi$. After the government re-enters, it regains good credit standing and has all its debt written-off. The government under default only chooses a tax rate and public spending to solve the following problem:

$$
V^{D}(z)=\max _{\tau \in \mathcal{T}, g}\left\{u\left(c^{*}, l^{*}, g\right)+\beta \mathbb{E}\left[(1-\xi) V^{D}\left(z^{\prime}\right)+\xi V\left(0, z^{\prime}\right)\right]\right\}
$$

subject to the government's budget constraint,

$$
g=\tau h(z) l^{*}
$$

where the private consumption $c^{*}$ and labor $l^{*}$ are determined by the optimality conditions (28) and (29) except that the productivity $z$ is replaced by its value under default: $h(z)$. 
Bond Price There is a continuum of risk-neutral foreign creditors that can lend and borrow in the international market at a risk-free rate $r^{*}$. They purchase the government bonds to maximize expected profits, which is given by

$$
\max _{b^{\prime}}\left\{-q\left(b^{\prime}, z\right) b^{\prime}+\mathbb{E}\left[\frac{1-d\left(b^{\prime}, z^{\prime}\right)}{1+r^{*}} b^{\prime}\right]\right\} .
$$

In each period, the discount bonds are issued by the domestic government at a price $q$ and their next period pay-offs depend on whether the government defaults or repays. The zero profit condition implies that

$$
q\left(b^{\prime}, z\right)=\frac{1}{1+r^{*}} \mathbb{E}\left[1-d\left(b^{\prime}, z^{\prime}\right)\right] .
$$

We focus on a Markov perfect equilibrium. That is, we assume that in each period, the government's equilibrium strategies depend only on payoff-relevant state variables.

Definition 2. A Markov perfect equilibrium under discretionary policy is characterized by a set of value functions $\left\{V, V^{R}, V^{D}\right\}$, policy rules $\left\{g^{R}, g^{D}, \tau^{R}, \tau^{D}, c^{R}, c^{D}, l^{R}, l^{D}, b^{\prime}, d\right\}$, and a bond price schedule $q$ such that: (1) Given the bond price $q$, the set of value functions and policy rules solves the government's optimal policy problem under repayment (31)-(32) and under default (33)-(34); (2) Given the default policy $d$, the bond price $q$ is determined by (36).

\subsection{Case 2: Non-Contingent Tax Commitment}

Under the non-contingent tax commitment, the government chooses a tax rate that is implemented in the next period. The state vector becomes $S^{(2)}=(b, \tau, z)$, where $\tau$ is the currently implemented tax rate decided in the last period. The borrowing and default decisions are similar to case 1. Under a good credit standing, the government chooses whether to repay or to default by comparing the corresponding values:

$$
V(b, \tau, z)=\max _{d \in\{0,1\}}\left\{(1-d) V^{R}(b, \tau, z)+d V^{D}(\tau, z)\right\} .
$$

The repaying government chooses the amount of borrowing and the next-period tax rate simultaneously,

$$
V^{R}(b, \tau, z)=\max _{\tau^{\prime} \in \mathcal{T}, b^{\prime}, g}\left\{u\left(c^{*}, l^{*}, g\right)+\beta \mathbb{E} V\left(b^{\prime}, \tau^{\prime}, z^{\prime}\right)\right\},
$$

subject to the budget constraint,

$$
g+b=\tau z l^{*}+q\left(b^{\prime}, \tau^{\prime}, z\right) b^{\prime}
$$

Different from case 1 , the current private consumption $\left(c^{*}\right)$ and labor $\left(l^{*}\right)$ are determined by the currently implemented tax rate $\tau$, which was set in the prior period. This assumption of one-period implementation lag captures the rigidity of changing fiscal policies in reality and it has been widely studied in the literature (i.e. Leeper et al., 2013). Here, we adopt this assumption to investigate the value of tax rate commitment during sovereign debt crises. The government under default is 
also subject to stochastic periods of exclusion from the financial market during which it suffers a productivity loss. Additionally, we assume that the government cannot adjust the tax rate anymore until it reenters the market. The value of default is defined as,

$$
V^{D}(\tau, z)=u\left(c^{*}, l^{*}, g\right)+\beta \mathbb{E}\left[(1-\xi) V^{D}\left(\tau^{\prime}=\tau, z^{\prime}\right)+\xi V\left(0, \tau^{\prime}=\tau, z^{\prime}\right)\right]
$$

where the government balances its budget by choosing the public consumption as $g=\tau h(z) l^{*}$, taking the private labor decision $l^{*}$ as given.

Bond Price Similar to case 1, the foreign creditors understand the government's default decision rule and charge a risk premium to compensate for their loss under default. Under the non-contingent tax commitment, the bond price schedule also depends on the committed tax rate in the next period $\tau^{\prime}$

$$
q\left(b^{\prime}, \tau^{\prime}, z\right)=\frac{1}{1+r^{*}} \mathbb{E}\left[1-d\left(b^{\prime}, \tau^{\prime}, z^{\prime}\right)\right] .
$$

A Markov perfect equilibrium under non-contingent tax commitment can be defined similarly as in case 1 , except that it has one additional policy rule - the committed tax rate $\tau^{\prime R}(b, \tau, z)$, chosen by the current government with a good credit standing.

\subsection{Case 3: Contingent Tax Commitment}

In this section, we discuss an economy where the government can commit to a schedule of tax rates that is a function of the next period productivity. Denote a functional set $\mathfrak{T}=\{\mathfrak{t}: Z \rightarrow \mathcal{T}\}$ which consists of mappings $(\mathfrak{t})$ from the productivity space $Z=\left[z_{\min }, z_{\max }\right]$ to the tax rate space $\mathcal{T}=\left\{\tau^{L}, \tau^{H}\right\}$. In each period, the government optimally chooses a contingent tax plan for the next period that is one element of this set of mappings: $\mathfrak{t}^{\prime} \in \mathfrak{T}^{\prime}$. Given the functional space $\mathfrak{T}$ has infinite dimensions, solving this problem directly involves solving maximization problems by choosing an infinite dimensional object, which is numerically infeasible. Even after we discretize the state space $Z$, the problem is still subject to the curse of dimensionality unless the number of grids on $Z$ is very small. However, given the assumption on the binary choice of the tax rate, we can prove that the problem can be transformed into choosing a threshold of the next period productivity within a certain interval that is called "crisis region". Only at the productivities higher than the threshold in the crisis region is the government willing to commit to the high tax rate. The detailed discussion about how to simplify the choice problem in case 3 and the numerical algorithm are in appendix C.

The state vector at the beginning of each period is the same as in case $2: S^{(3)}=(b, \tau, z)$. Here, $\tau$ indicates the implemented tax rate after the shock $z$ is realized. At the beginning of each period, the government chooses whether to default or to repay according to (37). For a repaying government, it chooses the bond issuance and the functional of contingent tax plan extended to the next period:

$$
V^{R}(b, \tau, z)=\max _{\mathfrak{t}^{\prime} \in \mathfrak{T}^{\prime}, b^{\prime}, g}\left\{u\left(c^{*}, l^{*}, g\right)+\beta \mathbb{E} V\left(b^{\prime}, \tau^{\prime}, z^{\prime}\right)\right\}
$$


subject to its budget constraint:

$$
g+b=\tau z l^{*}+q\left(b^{\prime}, \mathfrak{t}^{\prime}, z\right) b^{\prime}
$$

and the private equilibrium conditions (28) and (29). In the next period, the implemented tax rate depends on both the committed tax plan and the shock realization:

$$
\tau^{\prime}=\mathfrak{t}^{\prime}\left(z^{\prime}\right)
$$

In contrast to case 2 , the government in case 3 designs a menu of tax rates which influences the next period problem unevenly, depending on the upcoming shock realizations. As we will show below, at good states where default probability is negligible, the government's optimal plan is to follow the same tax rates as implied by a discretionary policy. The government has an incentive to adopt the austerity tax rate only at crisis states where the risk premium is sufficiently high. Overall, the ability to make tax commitment contingent on the state space reduces the cost of commitment and allows the government to borrow at a more favorable bond price in equilibrium. The bond price schedule $q\left(b^{\prime}, \mathfrak{t}^{\prime}, z\right)$ depends on the contingent tax plan (or after simplification, the chosen productivity threshold). Similar to case 2, we assume the government cannot adjust its tax rate during exclusion. The default problem becomes trivial and it is defined as:

$$
V^{D}(\tau, z)=u\left(c^{*}, l^{*}, g\right)+\beta \mathbb{E}\left[(1-\xi) V^{D}\left(\tau^{\prime}=\tau, z^{\prime}\right)+\xi V\left(0, \tau^{\prime}=\tau, z^{\prime}\right)\right]
$$

given the government's balanced budget $g=\tau h(z) l^{*}$ and the private optimality conditions.

Bond Price Denote the default decision of the government in case 3 as $d(b, \tau, z)$, which depends on debt balance, TFP shock, and the implemented tax rate. The bond price is determined by the default probability in the next period,

$$
q\left(b^{\prime}, \mathfrak{t}^{\prime}, z\right)=\frac{1}{1+r^{*}} \mathbb{E}\left[1-d\left(b^{\prime}, \tau^{\prime}=\mathfrak{t}^{\prime}\left(z^{\prime}\right), z^{\prime}\right)\right] .
$$

As shown in equation (46), the bond price depends on the new borrowing and the committed tax plan that will be implemented in the next period. In the current period, the government chooses the borrowing and committed tax plan simultaneously to maximize the current value. The mechanism driving this welfare improvement is the same as in the two-period model: a tougher fiscal policy could be suboptimal for the future government's problem, and deceases the continuing value in expectation. However, it benefits the current government by producing a more lenient bond price schedule and enhancing the households' welfare ex ante. As we will show in the numerical analysis below, the contingent tax schedule is a complicated object to compute (a non-monotonic function of shock realizations) and it implies that the careful design of a fiscal commitment device is a crucial part of the optimal policy for a sovereign default economy.

A Markov perfect equilibrium under the contingent tax commitment can be defined similarly as 
the above two cases, except that we have the policy rule of a contingent tax plan at each state: $\left[\mathfrak{t}^{\prime}\left(z^{\prime}\right)\right](b, \tau, z)$. Instead of committing to a single number of tax rate as in case 2 , the government designs the whole landscape of tax policies in the future under the contingent tax commitment.

\section{Quantitative Analysis}

This section presents the quantitative analysis of the full model. First, we calibrate the model to the Greek economy. Then, we discuss the effect of the fiscal commitment on the government's default incentive and compare the long-run statistics under different fiscal policies. Next, we perform a counter-factual analysis applied to Greek debt crisis and assess the contribution of being able to make tax commitments in reducing the sovereign risk premiums. Last, we conduct sensitivity analysis and examine how different austerity tax rates or risk aversion parameters affect our quantitative results. We also evaluate the cost necessary to prevent the government from abandoning its fiscal commitments.

\subsection{Calibration and Model Fit}

We calibrate the model under discretionary fiscal policy (case 1) to Greece using data from 1997Q1 to 2017Q3. We choose Greece since it has been experiencing a major sovereign crisis over the past 10 years and has conducted several rounds of fiscal austerity reforms. We borrow some of the parameter values from the sovereign default literature. We assume that the households' utility function takes the GHH form, which eliminates the wealth effect on labor supply:

$$
u(c, l, g)=(1-\pi) \frac{\left(c-\frac{l^{1+\phi}}{1+\phi}\right)^{1-\sigma}}{1-\sigma}+\pi \frac{g^{1-\sigma}}{1-\sigma} .
$$

The risk aversion parameter $\sigma$ is set to $2^{14}$, a standard value in the DSGE literature. The Frisch elasticity is set to the same value as in Cuadra et al. (2010), $1 / \phi=2.22$. The utility weight of public consumption $(\pi=0.182)$ follows Hatchondo et al. (2015). The persistence of TFP shock $\left(\rho_{z}=0.95\right)$ is in line with the real business cycle models in the literature with quarterly frequency (e.g. Gordon and Guerron-Quintana, 2017). The risk-free interest rate $r^{*}$ corresponds to the 3month U.S. treasury bill rate at $1 \%$. We set the probability of re-entrance $\xi$ to be $10 \%$ so that the government is banned from the financial market for an average of two and a half years after a default, following Aguiar and Gopinath (2006).

Following Hatchondo et al. (2015) and Gordon and Guerron-Quintana (2017), we assume a quadratic loss function on productivity during the exclusion episodes,

$$
h\left(z_{t}\right)=\left(1-\max \left(d_{0}+d_{1} z_{t}, 0\right)\right) z_{t}
$$

The last 4 parameters - discount factor $\beta$, TFP innovation size $\sigma_{z}$, and the parameters of default

\footnotetext{
${ }^{14}$ In the comparative analysis below, we confirm that our result is robust to setting a higher risk aversion parameter on public consumption: $\sigma_{g}=3$.
} 


\begin{tabular}{lcc} 
Description & Parameters & Value \\
\hline \hline From literature or simple moment & match: & \\
Relative risk aversion & $\sigma$ & 2 \\
Inverse Frisch elasticity & $\phi$ & 0.46 \\
Weigh on public consumption & $\pi$ & 0.182 \\
World free interest rate & $r^{*}$ & 0.01 \\
Probability of redemption & $\xi$ & $10 \%$ \\
TFP shock persistence & $\rho_{z}$ & 0.95 \\
\hline Calibrated to fit targets: & & \\
Discount factor & $\beta$ & 0.88 \\
Fixed default cost & $d_{0}$ & -1.086 \\
Proportional default cost & $d_{1}$ & 1.167 \\
TFP innovation size & $\sigma_{z}$ & 0.0142 \\
\hline
\end{tabular}

Table 2: Parameter Values under Baseline Calibration

cost $d_{0}, d_{1}$-are jointly set to target the following data moments: the average debt service-output ratio, the average interest rate spread (or default frequency ${ }^{15}$ ), the standard deviation of the spread, and the standard deviation of output. When calculating these data moments, we use the series of GDP, public and private consumption, and net export from the IMF's International Financial Statistics dataset (IFS). The Greek debt service is measured as the historical average of the government's interest payable we find from the Eurostat dataset. The interest rate spreads are the Greek 10-year government bond yields over 10-year German bond from the FRED database.

To set the normal time tax rate $\tau^{L}$ and the austerity tax rate $\tau^{H}$, we use a "two-step" calibration strategy. In the first step, given a set of parameters $\left\{\beta, \sigma_{z}, d_{0}, d_{1}\right\}$, we solve the model in case 1 but let the government choose the tax rates from a continuous range: $\tau \in[0,1]$. Then we simulate the economy and set the average tax rate over the entire simulation as the normal time tax rate $\tau^{L}$. On the other hand, we set $\tau^{H}$ to be the average tax rate during the periods when the interest rate on the government bond is four times higher than the average interest rate in the simulation. Therefore, $\tau^{H}$ is interpreted as the effective tax rate when the country is experiencing debt crisis and it roughly represents a tougher fiscal stance under the austerity. In the second step, we resolve the model with the choice of tax rates restricted to one of the two values: $\tau \in\left\{\tau^{L}, \tau^{H}\right\}^{16}$. Then, we compare the simulated moments from this reduced model with the moments in the data. If the distance between the two is small enough, then stop; otherwise adjust the set of parameters and go back to the first step.

Table 2 summarizes the parameter values and table 3 compares the moments in the data and those generated by the model. To calculate the model moments, we simulate the model for 1,000,000 periods and discard the first 10,000 periods. Following Hatchondo et al. (2015), in our simulated series, we identify the 74-periods event windows before default episodes in which no default occurs in the previous 26 periods. We report the average value for each moment across these identified

\footnotetext{
${ }^{15}$ With one-period bond and 0 recovery rate, the default probability is closely related to the average interest rate spread.

${ }^{16}$ In the numerical analysis below, we report the frequency for the government to choose the austerity tax rate $\tau^{H}$ and then compare the frequency of austerity tax rate among the three cases.
} 


\begin{tabular}{lcc} 
& $\begin{array}{c}\text { Greece } \\
\text { 1997Q1-2017Q3 }\end{array}$ & $\begin{array}{c}\text { Baseline Model } \\
\text { Discretionary Policy }\end{array}$ \\
\hline \hline Targeted Moments: & & \\
Debt service-output & $5.43 \%$ & $5.20 \%$ \\
Average spread (annualized) & $4.45 \%$ & $4.17 \%$ \\
Standard deviation of spread & $5.49 \%$ & $7.51 \%$ \\
Standard deviation of output & 12.53 & 11.76 \\
\hline Other Statistics: & & \\
Default probability & $2.80 \%$ & $3.40 \%$ \\
$\operatorname{std}(c) /$ std $(y)$ & 0.95 & 1.08 \\
$\operatorname{std}(g) /$ std $(y)$ & 0.94 & 1.58 \\
$\operatorname{std}(t b / y) /$ std $(y)$ & 0.25 & 0.165 \\
$\operatorname{corr}(c, y)$ & 0.98 & 0.99 \\
$\operatorname{corr}(g, y)$ & 0.95 & 0.89 \\
$\operatorname{corr}(t b / y, y)$ & -0.77 & -0.62 \\
$\operatorname{corr}(s p r e a d, y)$ & -0.41 & -0.66 \\
$\operatorname{corr}(y, y-1)$ & 0.97 & 0.77 \\
\hline
\end{tabular}

Note: When calculating the second moments in the data, GDP, private consumption, government consumption, and the trade-balance ratio (the ratio was added to one before taken log) were taken log and then detrended linearly. We report the deviations from the trend. The interest rate spread is in annual rate. The frequency of default for Greece comes from Reinhart and Rogoff (2009), which documents 5 default episodes from 1832 to 2009.

Table 3: Baseline Calibration: Model and Data

event windows. Table 3 shows that the model fits the data reasonably well, even for the untargeted moments. Our model captures some distinctive features of emerging economies: both the trade-balance and interest rate spread are counter-cyclical and the private consumption is highly correlated with output. One target that our model misses is that the model predicts that the consumption (both private and public) is more volatile than output, which is a common feature in sovereign default models. This is because the risk premiums make it difficult for the government to smooth consumption using the bonds, especially during economic recessions.

\subsection{Decision Rules with Dicretionary Fiscal Policy}

Figure 5 shows the bond price schedules and figure 6 displays the policy functions in the model with discretionary fiscal policy. As shown in figure 5, the government is more likely to default in the next period when it borrows more or when productivity is low since the productivity process is persistent. Given the bond price schedules, the government makes decisions on the level of borrowing, private and public consumption, and tax rates. As shown in figure 6, the government issues more bonds as the current debt level increases. However, the bond price deteriorates as the government borrows more since the probability that the government defaults in the next period rises. As a result, the government's ability to finance via borrowing declines and the public consumption (upper right panel) declines gradually as the debt level increases. On the other hand, private consumption (upper left panel), which is determined by the tax rate, is held constant at low debt states when the government maintains the normal time tax rate $\tau^{L}$.

As the debt level approaches the default threshold, the government switches to the high tax rate (austerity tax rate $\tau^{H}$ ). The tough fiscal policy increases government tax revenue and thus 


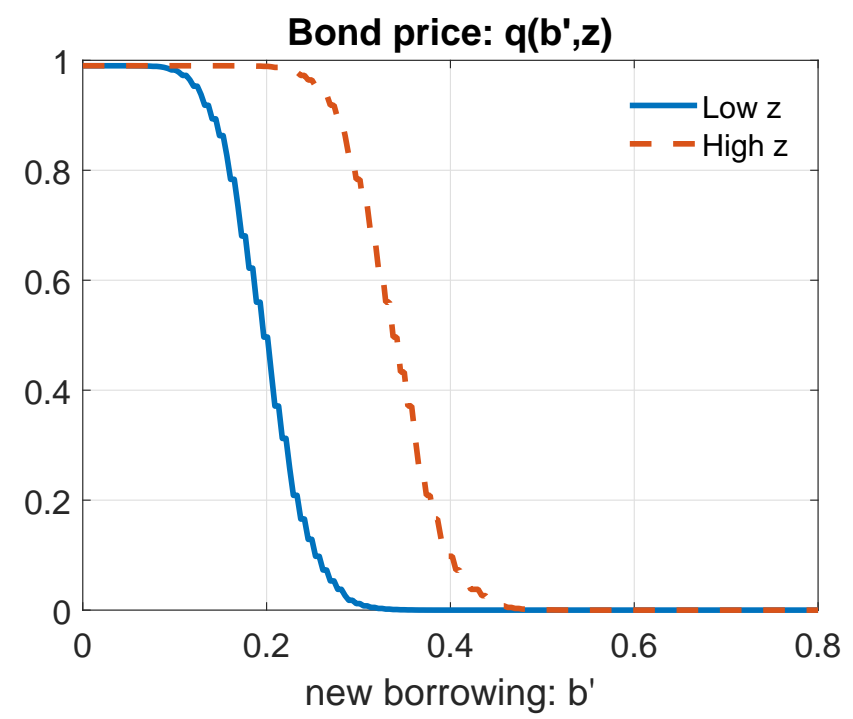

Note: The figure plots bond prices as functions of new borrowing when TFP is one standard deviation below (solid) or above (dashed) its unconditional mean.

Figure 5: Bond Price as a Function of New Borrowing under Discretionary Fiscal Policy

reduces the its external financing needs. Therefore, debt issuance $b^{\prime}$ has a slight decline when the government begins to use the high tax rate. Similarly, public consumption jumps up slightly as the government receives more tax revenue. On the other hand, the high tax rate reduces the resources that the households have for private consumption, so private consumption declines. Last, as the debt level continues to rise, the government's borrowing increases and public consumption decreases until the government defaults.

The feature that the high tax rate is implemented prior to default is consistent with Cuadra et al. (2010), which predicts that the optimal fiscal policy tends to be pro-cyclical when the country is subject to sovereign default risks. Our paper builds upon this result and, in the next section, we will show that the government's optimal fiscal policy under commitment is even more pro-cyclical. In that sense, we provide a context to understand why certain fiscal austerity reforms during crises are desirable for the debtor country governments in ex ante. The austerity measure, followed with a more stringent fiscal policy and enforced by third party institutions, effectively works as a commitment device for the government, helping it reduce its discretionary power and generating a more lenient bond price.

\subsection{Comparing Tax Commitments}

A policy question under discussion is whether the austerity commitment during the recent European debt crisis can help the countries recover from the crisis and create borrowing opportunities. In this section, we compare the decision rules under the three fiscal policy structures described above. The upper left panel of figure 7 plots the debt Laffer curves faced by governments as functions of new debt issuance $b^{\prime}$ in all the three cases. As in the two-period model, commit- 

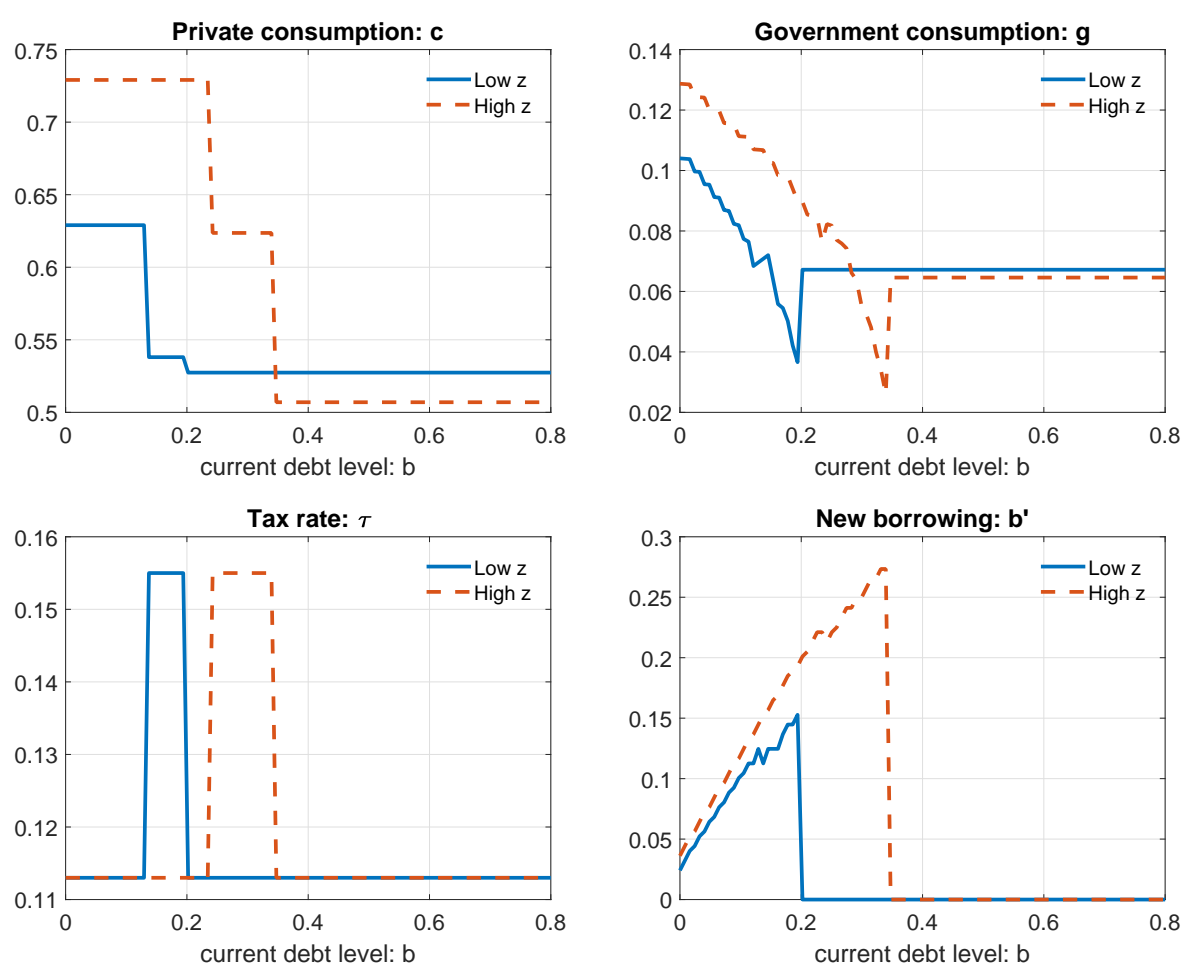

Note: The figures plot the decision rules for private and public consumption, tax rate, and new borrowing as functions of current debt level when the TFP is one standard deviation below (solid) or above (dashed) its mean.

Figure 6: Decision Rules under Discretionary Fiscal Policy

ting to the high tax rate in the future allows the government to suppress the next-period default incentives. Therefore, compared to the case of discretionary fiscal policy, tax commitments can reduce the probability of default for every level of borrowing and create more favorable bond prices. Moreover, the commitment effect is larger under a contingent tax commitment since it allows the government to conduct a pro-cyclical fiscal policy. As a result, the debt Laffer curves move to the right when the government can make commitments, especially for the contingent tax commitment. When the government borrows more easily, it provides more public consumption when repaying its debt (upper right panel of figure 7).

How does the fiscal commitment affect the government's ability to borrow? First, we define the equilibrium bond price as ${ }^{17}$,

$$
q^{c}(b, z)=q\left(b^{\prime}(b, z), z\right)
$$

and the interest rate spread in equilibrium is $\left(1 / q^{c}(b, z)-\left(1+r^{*}\right)\right) \times 400 \%$. The lower right panel of figure 7 compares the equilibrium spreads at each level of debt. Note that even when the economy borrows more and becomes more indebted under the fiscal commitments, interest rate spreads at the optimal level of borrowing are still lower compared to the case of discretionary policy. The lower

\footnotetext{
${ }^{17}$ In general, tax commitment impacts both the government's optimal borrowing and bond price (defined on each level of borrowing) simultaneously. To make the three cases comparable, the equilibrium bond price seems to be a more natural measure indicating how the fiscal commitment helps the government reduce its default risk at the borrowing decisions it is willing to make.
} 

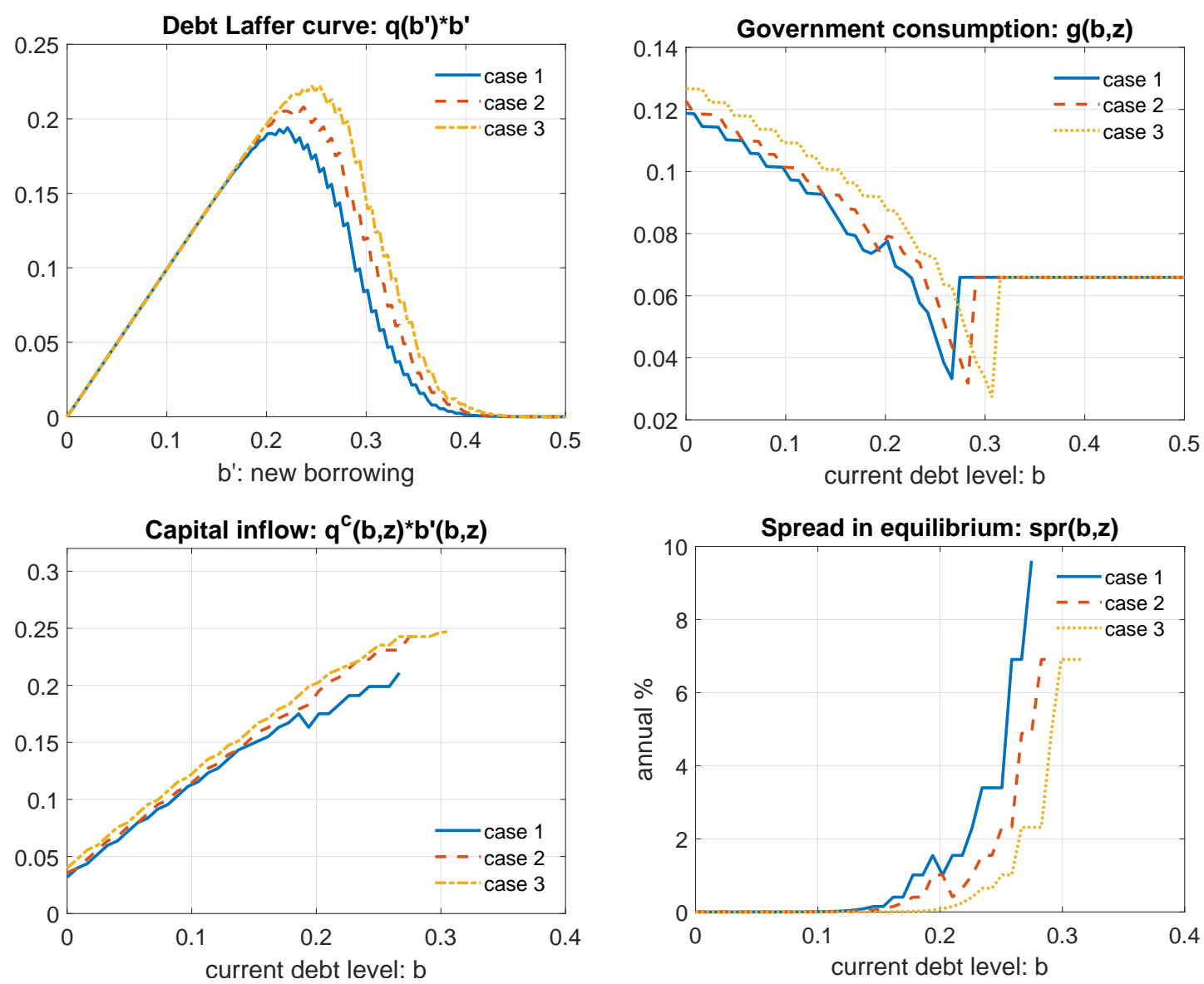

Note: This figure compares the debt laffer curve, public consumption, capital inflow, and equilibrium spread in all three cases. The equilibrium bond price is calculated according to equation (49).

Figure 7: The Effects of Tax Commitments

left panel shows the policy of capital inflows. By mitigating default risk, the fiscal commitments greatly relaxes the country's borrowing constraint, especially at high debt levels, inducing more capital inflows. The net increase of capital inflows partly comes from the higher equilibrium bond price $q^{c}(b, z)$, with the rest coming from the increased level of borrowing $b^{\prime}(b, z)$.

Compared to the case of non-contingent tax commitment, the government with contingent tax commitment can further reduce bond spreads and increase the government's ability to borrow. This is consistent with the intuition from the two-period model. Under contingent commitment, the government only needs to commit to the austerity tax rate $\tau^{H}$ in bad states that are close to the default threshold. This contingency reduces the commitment cost and allows the government to use it more aggressively. As a result, compared to the other two cases, the government with contingent tax commitment attains the largest borrowing and the smallest interest rate spread for each level of indebtedness.

Figure 8 compares tax policies in all three cases at each combination of the next-period productivity $z^{\prime}$ and current level of debt $b$. We assume that the current productivity is at its mean. Specifically, starting from the current state $(b, z=\bar{z})$, let the governments choose their optimal 


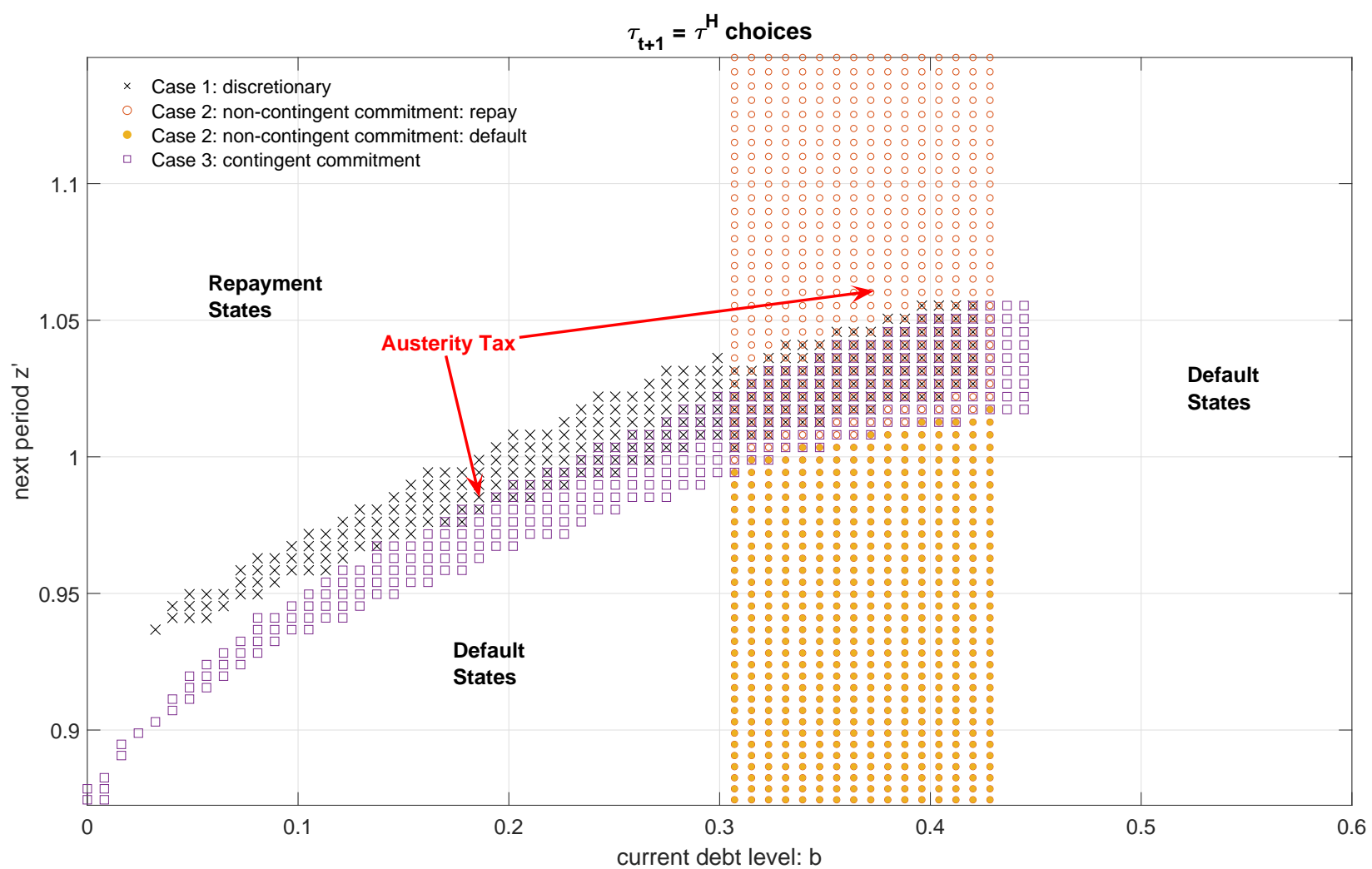

Note: This plot shows the combinations of current debt $b$ and next-period $z^{\prime}$ that the government under different types of tax commitments implements the austerity tax rate $\tau^{\prime}=\tau^{H}$. Current productivity is assumed to be at its mean $z=\bar{z}$. For each case, we assume that the governments make their borrowing decisions according to the equilibrium decision rules. In case 2 , the filled circles indicate default states in the next period, while the empty ones are repayment states.

Figure 8: States that the Government Implements the Austerity Tax Rate

levels of borrowing $b^{\prime}=b^{\prime}(b, \bar{z})$. Then, for case 1 , the next period government will make the tax policy in a discretionary manner: $\tau^{\prime}=\tau\left(b^{\prime}, z^{\prime}\right)$. For case 2 , today's government commits to a single tax rate $\tau^{\prime}(b, \bar{z})$ that applies to all values of productivity in the next period. For case 3, today's government commits a schedule of tax rates contingent on the next period productivity realizations: $\mathfrak{t}^{\prime}\left[z^{\prime}\right](b, \bar{z})$. In figure 8 , the grid points with markers indicate the combination of $b$ and $z^{\prime}$ where the government implements the austerity tax rate in the next period: $\tau^{\prime}=\tau^{H}$. For case 2 , the filled circles indicate default states in the next period, while the empty ones are repayment states.

As we can see, the shapes of fiscal policy rules are quite different between the two types of fiscal commitment. In case 2, once the government commits to the austerity tax, it applies to all values of productivity in the next period, including both the ones that government defaults and repays. On the other hand, for a given level of debt, the case 3 government only commits to implement austerity around a TFP threshold below which the government will default. In figure 8 , this state-contingency feature makes the austerity region look more similar to the case 1 when the government uses the discretionary policy, only except that the case 3 government shifts down the 

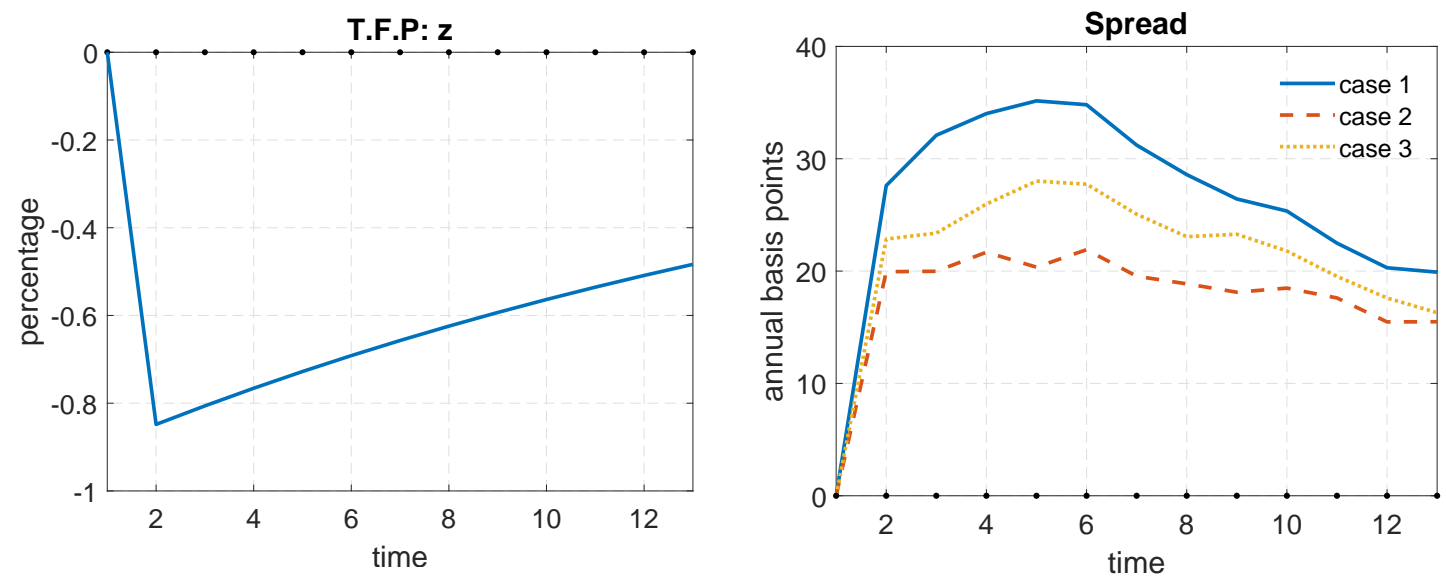

Note: The figures plot the generalized impulse responses of the three economies under a negative productivity shock of $60 \%$ standard deviation. We label the impact period as 1 .

Figure 9: Impulse Responses of the Spread to a Negative Productivity Shock

austerity region (the region with markers) to an area with lower $z^{\prime}$. This is because committing to a tax plan forces the future government to repay for a wider range of productivity and shrinks the default region in the next period compared to the case 1. Additionally, by comparing case 3 with case 2, we can see that committing to a tax plan has a stronger effect in reducing default probability than committing to a single tax rate, and the default threshold of $z^{\prime}$ is lower in case 3 than in case 2 for each level of $b$. The same argument applies if we look at tax policies at different debt levels. Austerity commitments allow the government to sustain a higher level of debt and the government in case 3 has the greatest ability in reducing default incentives and thus attains the highest debt sustainability.

Impulse Responses We compare the impulse responses to a negative TFP shock for all three cases in the model in order to investigate the shock transmission under different fiscal policies. In our non-linear model, the impulse responses are constructed using the method introduced in Koop et al. (1996). First, we simulate the economy for 1050 periods and for 5000 paths of shocks. Next, we simulate the economy again with the same set of shocks but decrease the productivity at period 1001 by $60 \%$ of its standard deviation. From period 1001 on, productivity follows the conditional Markov chain. The generalized impulse responses are calculated as the averaged difference between the paths with and without the shock, conditional on remaining in good credit standing. Figure 9 displays the impulse responses of the productivity and sovereign spreads in the models with and without commitment. As shown in the figure, fiscal commitment allows the government to ameliorate default incentives and therefore yields a smaller increase in the spreads under a negative productivity shock, both on impact and after the shock hits.

Long-run Simulation Table 4 presents the long-run statistics of the model under different types of fiscal commitments. First of all, under both the non-contingent and contingent tax commitments, 
Case 1

Case 2

Case 3

\begin{tabular}{lccc} 
& Discretionary Policy & Non-Contingent Commitment & Contingent Commitment \\
\hline \hline std $(g) /$ std $(y)$ & 1.58 & 1.43 & 1.54 \\
$\operatorname{corr}(\operatorname{spread}, y)$ & -0.66 & -0.56 & -0.61 \\
$\operatorname{corr}(\tau, y)$ & -0.55 & -0.61 & -0.61 \\
\hline Debt service-ratio (\%) & 5.20 & 5.79 & 6.94 \\
Average spread (\%) & 4.17 & 3.90 & 4.61 \\
Default probability (\%) & 3.40 & 3.22 & 3.16 \\
Austerity frequency (\%) & 8.7 & 14.7 & 12.0 \\
Welfare gain (\%) & - & 0.26 & 0.96 \\
\hline
\end{tabular}

Note: (a) To calculate the second order moments, we simulate the model for 1,000,000 periods and discard the first 10.000 periods. we create the event windows of 74 periods before default in which no default occurs in the previous 26 periods. The numbers are the mean value of each moment across all event windows found. (b) Numbers in the bottom panel are in percentage term. The welfare gain is the percentage of permanent consumption that the government is willing to pay moving from an economy with discretionary policy to an economy with fiscal commitment. The welfare gains are averaged across states based on the Ergodic distribution of the baseline economy.

Table 4: Long-run Statistics under Different Types of Tax Commitments

the government is more willing to implement tax reforms during economic recessions to reduce the probability of default and the risk premium. As a result, the tax policies are more pro-cyclical and spreads are less counter-cyclical compared to the case of discretionary policy. In addition, the mitigated default risk under both types of commitment enhances the government's ability to smooth consumption and reduces the volatility of public consumption.

The mitigated default risk under both types of tax commitment also encourages borrowing and increases the average level of debt. As a result, table 4 shows that the average debt service to GDP ratio is higher under the tax commitments and the highest under the contingent commitment. Since fiscal commitment reduces default risk but makes the economy more indebted, the final effects on the interest rate spread or default probability is not certain. We find the average spread decreases in case 2 but increases in case 3 . However, default probability is always lower under fiscal commitments compared to the economy in case 1. During the episodes of debt crisis, the government under fiscal commitment is better-off by choosing austerity and repaying rather than choosing to outright default on its debt. This is evident in that the commitments increase the frequency that the government implements the austerity tax compared to the discretionary policy. Moreover, since the contingent tax commitment is more effective in reducing default risk, the austerity frequency is lower in case 3 than in case 2 .

Welfare Gains By committing to a tougher fiscal policy in the future, the government under fiscal commitments has greater ability to control its default incentives. The mitigated default risk implies a lower financing cost, which benefits the home country. On the other hand, the fiscal commitment is also associated with the higher degree of fiscal rigidity, resulting in a loss of non-contingency in the tax policy. In addition, the government tends to borrow more heavily when the fiscal commitment mitigates the default risk, and becomes more indebted in the limiting 


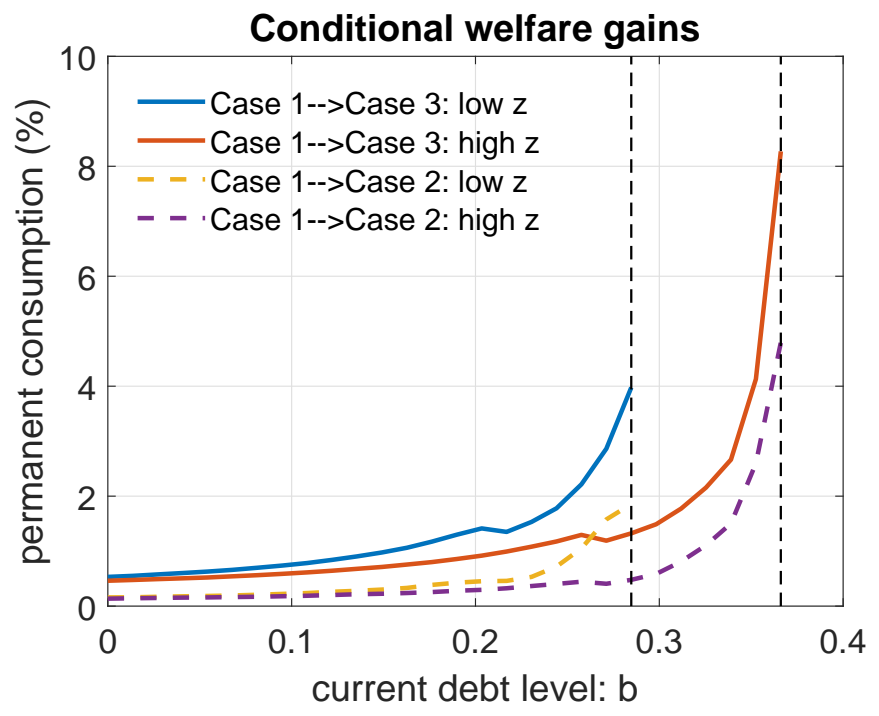

Note: The vertical axis represents the percentage of permanent consumption that the government is willing to pay in order to move from an economy with discretionary policy to an economy with contingent or non-contingent tax commitments. The productivity levels here are 0.5 standard deviation below and above the mean and the welfare gains are only calculated when the government is repaying its debt.

Figure 10: Conditional Welfare Gains of Tax Commitments

distribution. Therefore, the welfare consequence of tax commitments depends on the relative strength of these benefits and costs. Figure 10 shows the state-contingent welfare gains from imposing tax commitments relative an economy with the discretionary policy. First, commitment on austerity tax always produces a welfare gain at all debt levels at repayment states. The welfare gain of contingent tax commitment is even larger than that of non-contingent commitment due to its ability to conduct a pro-cyclical fiscal policy. Second, the size of the welfare gains highly depends on the debt levels. Consistent with our intuition, the net welfare benefit of fiscal commitment is more prominent at high debt states around the default thresholds where the tax commitment is more useful to reduce the default risk. As shown in the bottom line of table 4, fiscal commitments generate significant welfare improvements on average due to the mitigated default risks and increased levels of borrowing. Relative to the case of discretionary policy, the austerity policy with non-contingent commitment increases the social welfare by $0.26 \%$, and the contingent commitment policy produces a larger welfare gain of $0.96 \%$.

\subsection{Event Analysis}

In this section, we take our model to the recent Greek debt crisis and use the model as a labotary to analyze the effect of austerity commitment on the default risk and the government bond spread. We conduct the following numerical experiment. First, we detrend the GDP and government consumption linearly before fitting the model with the data. Given the time paths of detrended GDP and government spending observations over 1997Q3 to 2017Q3, we estimate the realization of the model-implied variables using the model with discretionary fiscal policy and the bootstrapped 

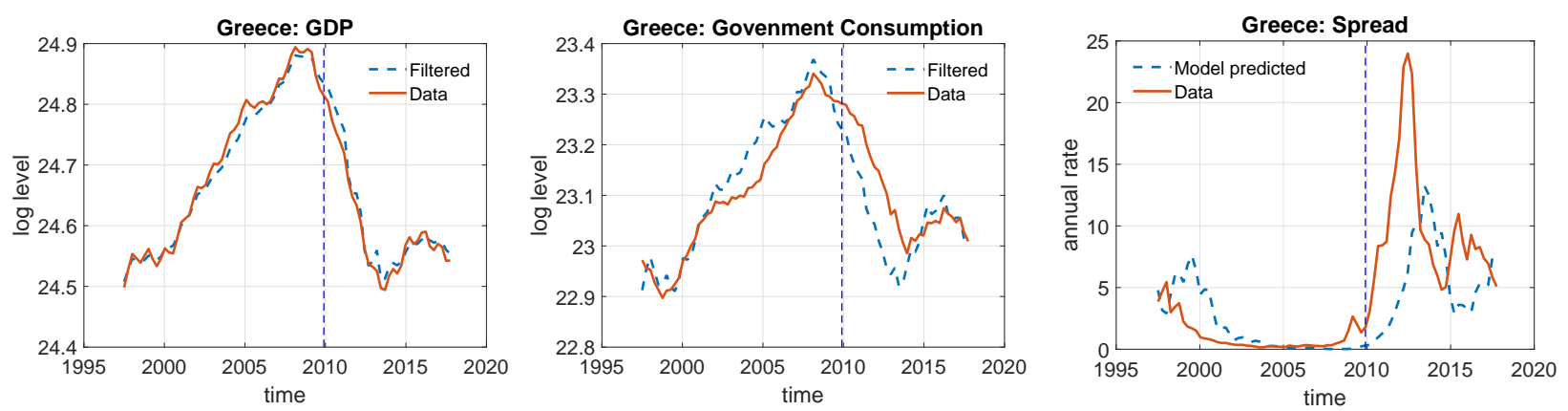

Note: The solid lines are time series of the data and the dashed lines are the model predicted ones. Both GDP and government consumption are data observables in the state-space model which we use to estimate other state variables. The dashed series of spread is predicted by the particle filter.

Figure 11: Case of Greek Debt Crisis: Data and Model Fit

particle filter as in Herbst and Schorfheide $(2015)^{18}$. We extract the path of shock realizations and the spread series from the model. Second, taking the 2009Q4 as the initial period, we feed-in the sequence of subsequent shock realizations to the models with fiscal commitment (case 2 and case 3). The counterfactual experiment represents an unexpected and permanent policy regime switch where government attains the ability to make commitment on future tax rates from $2010^{19}$. We then investigate the timing that austerity is implemented by the government with commitment and compare the model-predicted spreads.

Figure 11 compares the GDP, government consumption, and interest rate spread in the data and corresponding model-implied series. As shown in the figure, the model generally captures the fluctuations of GDP and government consumption in the data. However, during the deep recession after 2010, the predicted government consumption deviates downward from the data counterpart because our state-space model only has one shock but is used to match two data observables. Even though it is not targeted, the model predicts a spike of the spread after 2010. Compared to the data, the spread in the model increases more gradually and reaches its peak in 2013, almost 1 year later than the peak in the data. The predicted spread in the model is also milder compared to that in the data. This latter result is reasonable since our model only has short-term debt but most of the external debt of Greece has a long duration ${ }^{20}$.

We next feed-in the extracted path of productivity shocks to the models with fiscal commitment from 2009Q4, the starting quarter of Greek debt crisis. We are specifically interested in whether the Greek government has incentives to conduct fiscal austerity reforms (implement the austerity tax) during the crisis and whether these commitment measures help it reduce default incentives and the spreads. Figure 12 shows that, compared with the discretionary fiscal policy, the Greek government indeed has lower spreads in most times during the crisis under commitment. In addition, the timing of the implementation of the austerity tax rate is different between the two fiscal commitment

\footnotetext{
${ }^{18}$ The full description of the state-space model is in appendix B.

${ }^{19}$ ECB started to intervene the Greek debt market since 2010 and austerity measures were proposed from then on.

${ }^{20}$ From the theoretical side, the sovereign default model with long-term debt can have a higher interest rate spread in normal times because of the dilution risk (see, Hatchondo and Martinez, 2009, for example).
} 


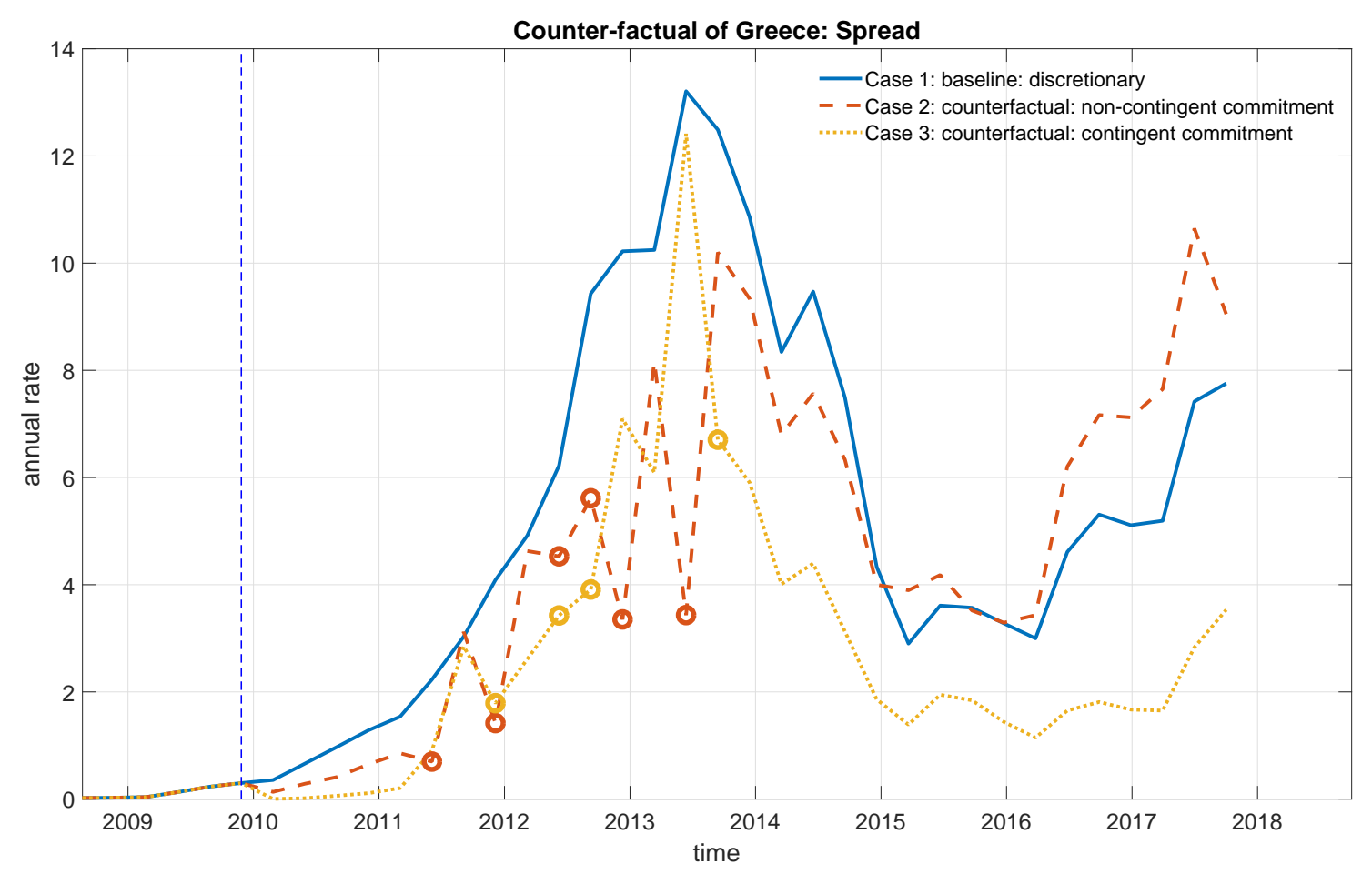

Note: Case 1 is the economy with discretionary fiscal policy which is filtered to the data of Greece. The dashed and dotted lines are the counterfactual interest rate spreads where we feed the extracted shock realizations into the models of case 2 and 3. The thick circles indicate the dates when the governments implement the austerity tax rate in the models.

Figure 12: Greece: The Effect of Fiscal Commitment on Spread

cases. Since the contingent tax commitment policy has a negligible commitment cost and is more effective in reducing the default risk, there are fewer total austerity points and the earliest date for the government to implement austerity is later than in case 2. On the other hand, the case 2 government is quite restricted by the fiscal rigidity associated with the non-contingent tax policy. As a result, we find in figure 12 that the government has to use the austerity tax rate whenever the spread increases, resulting in more frequent fiscal adjustments. The lower austerity frequency for the government in case 3 is also consistent with our long-run simulation result in table 4.

\subsection{Comparative Statics}

This section examines the sensitivity of our results to some of our assumptions and the parameter values. First, in our model we assume that the government can only implement either the normal time tax rate $\left(\tau^{L}\right)$ or the austerity tax rate $\left(\tau^{H}\right)$ and the distance between these two indicates the size of austerity reforms. To check the implications of this assumption, we vary $\tau^{H}$ and investigate how the welfare results depend on the size of the austerity. Second, the risk aversion parameter on public consumption plays an important role in our model since it governs the government's incentives to smooth consumption and also to default. Therefore, we re-examine our results in a model with a higher risk aversion on public consumption. Last, up to now, we study the effect of 


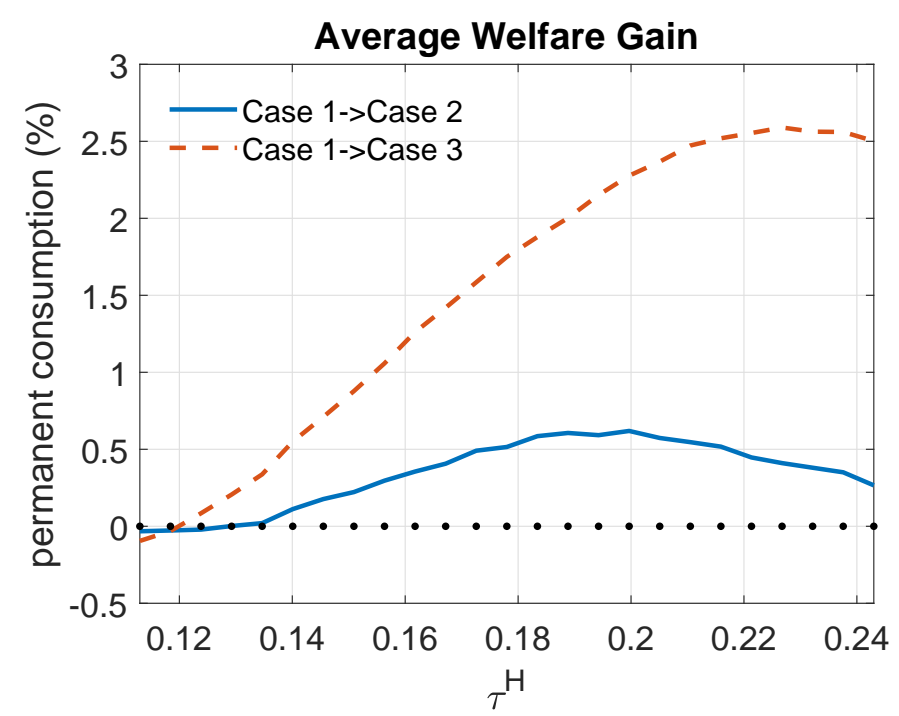

Note: For each value of $\tau^{H}$, the y-axis value indicates the average percentage of permanent consumption the government would like to pay to move from an economy with discretionary fiscal policy (case 1) to an economy with non-contingent tax commitment (case 2 in solid line) or with contingent tax commitment (case 3 in dashed line). The numbers are averaged based on the Ergodic distribution of the baseline economy.

Figure 13: Welfare Results Under Different Austerity Tax Rates

fiscal commitment assuming the commitment devices are naturally attached to austerity measures and are always enforceable. However, as introduced before, the austerity measures in most countries are enforced by international institutions or supranational policy-makers, which makes it relevant to consider the cost of enforcing such commitment. Specifically, we evaluate how much costs would be enough to prevent the government from abandoning its committed fiscal rules.

Size of Austerity We fix the normal time tax rate $\tau^{L}$ as in the baseline calibration and vary the austerity tax rate $\tau^{H}$. For each value of $\tau^{H}$, we solve all three models with different fiscal polices and simulate the economies in the same ways as before. Figure 13 plots the average welfare gains of moving from a case 1 economy to case 2 or case 3, respectively. As $\tau^{H}$ increases and deviates from $\tau^{L}$, the value of fiscal commitment becomes stronger conditional on that the government is still willing to implement it. However, a very high austerity tax rate may reduce the frequency of implementing the austerity and therefore weaken the effect of being able to make commitments. Apart from this ex ante trade-off, a tougher austerity also imposes greater ex post costs after the austerity is implemented. As a result, figure 13 shows that the welfare gains for both fiscal commitment devices are hump-shaped with respect to the austerity tax rate $\tau^{H}$.

Figure 13 also shows that at each austerity tax rate, the contingent tax commitment always results in a larger welfare improvement than the non-contingent tax commitment. Moreover, compared to the non-contingent policy, the welfare gains of the contingent tax commitment reach the peak at a higher value of austerity tax rate. Again, such difference is caused by the feature that the contingent tax commitment can preserve a pro-cyclical fiscal policy and engage a smaller commitment cost. A 
Case 1

Case 2

Case 3

\begin{tabular}{lccc} 
& Discretionary Policy & Non-Contingent Commitment & Contingent Commitment \\
\hline \hline Debt service-ratio (\%) & 5.30 & 5.35 & 5.86 \\
Average spread (\%) & 3.87 & 3.72 & 4.41 \\
Default probability (\%) & 3.15 & 3.03 & 3.69 \\
Austerity frequency (\%) & 6.0 & 8.8 & 7.7 \\
Welfare gain (\%) & - & 0.07 & 0.63 \\
\hline
\end{tabular}

Note: The simulated moments are calculated in the same ways as in table 4.

Table 5: Long-run Statistics with $\sigma_{g}=3$

government equipped with this better commitment device is willing to adopt a larger austerity size. Finally, in appendix E, we see the austerity frequencies decline when the size of austerity increases, but this decline is faster in case 2 than in case 3. In addition, we show the effects of $\tau^{H}$ on the probabilities of default, average debt levels, and average spreads in the models with different types of tax commitment.

Risk Aversion Under the baseline calibration, we make the assumption that the relative risk aversion on private consumption and public consumption are the same. An alternative assumption used in existing papers (e.g. Hatchondo et al., 2015) is that households are more sensitive to fluctuations in public consumption. Since the risk aversion parameter has a substantial impact on the government's consumption-smoothing and default incentives, we examine whether our results are robust to a change of the risk aversion parameter. The form of utility function is the same,

$$
u(c, l, g)=(1-\pi) \frac{\left(c-\frac{l^{1+\nu}}{1+\nu}\right)^{1-\sigma}}{1-\sigma}+\pi \frac{g^{1-\sigma_{g}}}{1-\sigma_{g}},
$$

except that the parameter $\sigma_{g}=3$. First, we re-calibrate the model to the Greek data using the same set of parameters ${ }^{21}$. Then, we simulate the economies under different types of tax commitments and report the long-run statistics in table 5 .

From table 5, we see that the same mechanism is still present when the government becomes more risk averse to the public consumption fluctuations. The austerity commitment mitigates the default risk during crises and enables the government to borrow at more favorable bond prices. This induces them to borrow more, leaving default probabilities and spreads largely unchanged. Similar to the baseline calibration, we find both tax commitments result in higher debt service ratios. The average spread in case 2 is slightly lower than in case 1 but the spread in case 3 is higher. Given that the contingent tax commitment largely increases the average indebtedness of the economy, the government in case 3 also defaults more frequently. In addition, note that the government in case 2 is engaged in more frequent austerities than in case 3 since the non-contingent tax commitment is a less effective way than the contingent commitment in managing the default risk. However, compared

\footnotetext{
${ }^{21}$ The calibrated parameters and moment match are shown in appendix D.
} 
to the baseline calibration, the higher risk aversion makes the government more reluctant to reduce public consumption during crisis. Intuitively, this makes the fiscal commitment less valuable in mitigating the default risk and in creating borrowing opportunities. We can see from the last row of table 5 that when $\sigma_{g}=3$, both tax commitment devices create smaller welfare improvements over the discretionary fiscal policy.

Cost to Enforce Commitment Next, we find the cost that would prevent the government from abandoning the fiscal commitment policies $^{22}$. Specifically, we consider the penalty needed to prevent deviations from the promised tax rates. For example, in case 2, suppose the current tax rate is $\tau^{L}$ and the fundamental states of the economy is $(b, z)$, the expected value associated with the one-period deviation is

$$
\hat{V}^{R}\left(b, \tau^{H}, z ; x\right)=u\left(c^{*}(1-x), l^{*}, g^{*}\right)+\beta \mathbb{E} V\left(b^{*}, \tau^{*}, z^{\prime}\right) .
$$

Let $x$ denote the cost (in terms of percentage consumption) incurred if the government surprises lenders and abandons the promised tax rate for one period. For each combination of debt and productivity, we find the value of $x^{*}$ such that $\hat{V}^{R}\left(b, \tau^{H}, z ; x^{*}\right)=V^{R}\left(b, \tau^{L}, z\right)$. A positive value of $x^{*}$ indicates a cost necessary for preventing deviations from the original tax rate $\tau^{L}$. The problem when the country is under the high tax rate or for the government in case 3 can be defined similarly.

Figure 14 plots the enforcement costs that is necessary to prevent the government's deviations from the committed tax rate at different levels of debt balance. The government's incentive to deviate from the promised tax rate is different in case 2 and case 3 . In case 2 , the non-contingent tax policy prevents the government from adjusting its tax rates based on shock realizations. However, in case 3, the non-contingency problem does not exist and the government has an incentive to deviate from the committed tax rate only when the government wants to default and switching to a different tax rate results in the higher value under default. Therefore, figure 14 shows that the case 2 government has incentives to renege on the tax commitment for a wide range of debt levels, but in case 3 the deviation incentives only appear at the debt levels close to the default threshold. On average, we find the enforcement cost needed to sustain a non-contingent tax commitment device is $0.2 \%$ of consumption, but to implement a contingent tax commitment, the enforcement cost is only $0.07 \%^{23}$.

Generally, we find that imposing a relatively small penalty on consumption would be enough to prevent the government from reneging on the tax commitment policies. A smaller enforcement

\footnotetext{
${ }^{22}$ There are two main considerations: First, we only consider the cost associated with a one-period deviation from the committed tax rate. As discussed in the previous sections, the general equilibrium effect of the fiscal commitment is to improve the government's ability to borrow. Therefore, abandoning the rule for multiple periods will discount the value of commitment on bond prices and thus decreases welfare. As a result, the cost to prevent a one-period deviation that we calculate in this section can also prevents the government from abandoning the commitment rule for multiple periods. Second, instead of reporting an enforcement cost in terms of productivity loss, we calculate the cost as the percentage of current consumption. This is because changing the productivity also alters the government's decision on tax rates. But we want a proxy to indicate the government' ex post incentives to deviate from the promised tax policy. Using the percentage of consumption provides a more reasonable and straightforward comparison.

${ }^{23}$ Here we focus on the enforcement costs when the government is repaying.
} 

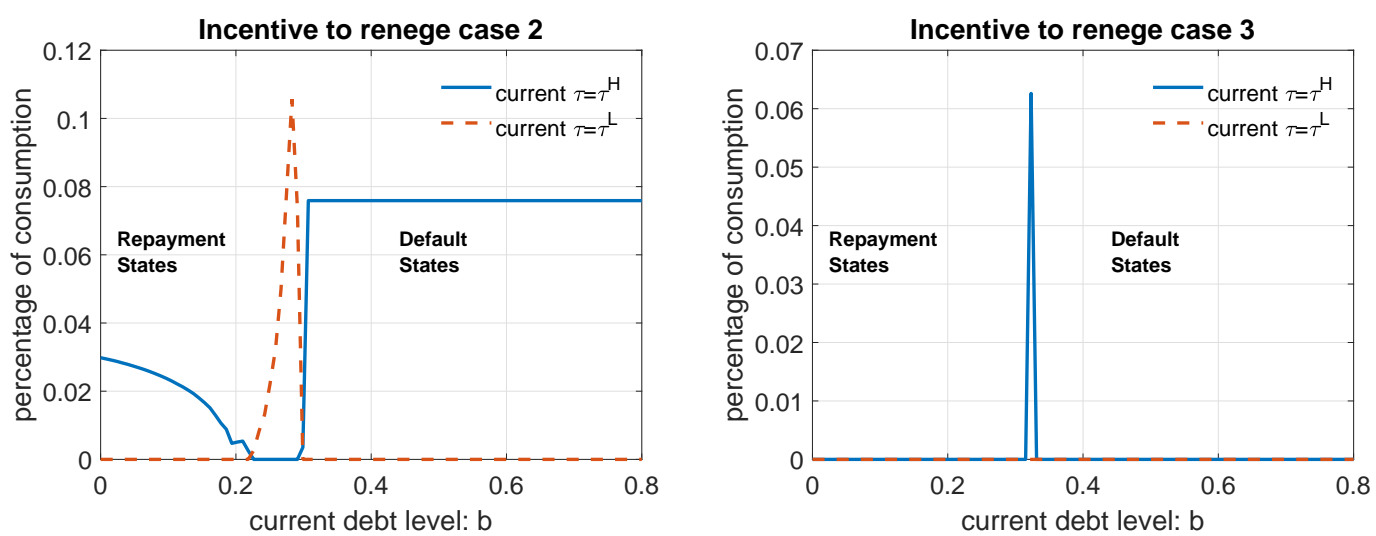

Note: The left panel shows the cost, in the percentage of consumption, needed to prevent the government in case 2 from reneging on the committed tax rates. The right panel shows the similar cost for the government in case 3 . We assume that the current productivity $z$ is at its mean.

Figure 14: Costs to Prevent a One-period Deviation of Committed Tax Rates

cost is needed to make the government follow the contingent commitment policy, which means the government is more self-constrained in that case. The difference in enforcement costs between the two cases highlights the advantage in choosing a flexible commitment device.

Throughout this paper, we assume the commitment devices are always available and we evaluate the welfare contribution of imposing fiscal commitment to the indebted economies. However, on the theory side, the commitment problem stems from the failure of the debtor to incorporate the externality of its choice of fiscal policy on the bond price. Since lenders are risk-neutral, from the $e x$ ante point of view, there always exists an insurance contract that leads to the welfare improvement, in the spirit of Coase theorem ${ }^{24}$. The enforcement costs here lend support to this view and show that the cost of that insurance is not large.

\section{Conclusion}

During the recent debt crisis, the Greek government agreed to perform fiscal austerity reforms in exchange for financial aid packages from the Eurozone leaders and the IMF. However, the economic impact of austerity during sovereign debt crises remains uncertain. Why the Eurozone leaders and IMF insist on the austerity reforms during the Greek sovereign debt crisis? How does accepting these austerity measures affect the government's incentive and ability to repay outstanding debt? This paper address these two questions by analyzing the interaction between fiscal commitment and sovereign default risk in a quantitative model.

This paper builds a sovereign default model with the optimal taxation and government spending. We find that the government suffers a time-inconsistency problem when it conducts a discretionary fiscal policy. Specifically, the government defaults too frequently and it is reluctant to make fiscal adjustments to repay its debt. The excessive default incidence is priced by foreign creditors which in

\footnotetext{
${ }^{24}$ This is also pointed out by Gonçalves and Guimaraes (2015)
} 
turn hurts the government's ability to borrow. Building on this mechanism, we evaluate two types of fiscal commitment devices: a non-contingent tax commitment and a contingent tax commitment. By promising a tougher fiscal policy in the future, both commitments enable the government to suppress the default incentive and increase its debt sustainability. However, the non-contingent commitment prevents the government from adjusting its tax policy based on shock realizations and results in an ex post welfare loss. In contrast, by tailoring a tax plan based on future economic states, the contingent tax commitment enjoys a smaller commitment cost and is more effective in reducing the default risk, leading to the larger welfare gain. Additionally, we show that imposing a small cost would be enough to prevent the government from abandoning the tax commitments, and the cost necessary to enforce the contingent tax commitment is smaller than cost for the non-contingent tax commitment.

Our findings highlight the importance of fiscal commitment in managing the sovereign risk and also rationalize the ECB's continuous efforts in enforcing austerity reforms on the European debtor countries under debt crises. This paper finds that the commitment to a stringent fiscal policy benefits the home country at the time of debt issuance and alleviates the severity of crises. In addition, the results of this paper also point out that a rigid austerity plan can be sub-optimal ex post and the commitment on fiscal policies should be flexible to accommodate the changes in future economic conditions. 


\section{References}

Aguiar, M. and G. Gopinath (2006). Defaultable debt, interest rates and the current account. Journal of international Economics 69(1), 64-83.

Arellano, C. (2008). Default risk and income fluctuations in emerging economies. The American Economic Review 98(3), 690-712.

Arellano, C. and Y. Bai (2017). Fiscal austerity during debt crises. Economic Theory 64(4), 657-673.

Bi, H. (2012). Sovereign default risk premia, fiscal limits, and fiscal policy. European Economic Review 56(3), 389-410.

Cuadra, G., J. M. Sanchez, and H. Sapriza (2010). Fiscal policy and default risk in emerging markets. Review of Economic Dynamics 13(2), 452-469.

Eaton, J. and M. Gersovitz (1981). Debt with potential repudiation: Theoretical and empirical analysis. The Review of Economic Studies 48(2), 289-309.

Gonçalves, C. E. and B. Guimaraes (2015). Sovereign default risk and commitment for fiscal adjustment. Journal of International Economics 95(1), 68-82.

Gordon, G. and P. A. Guerron-Quintana (2017). Dynamics of investment, debt, and default. Review of Economic Dynamics.

Hatchondo, J. C. and L. Martinez (2009). Long-duration bonds and sovereign defaults. Journal of international Economics 79(1), 117-125.

Hatchondo, J. C., L. Martinez, and F. Roch (2015). Fiscal rules and the sovereign default premium. Available at SSRN 2625128.

Herbst, E. P. and F. Schorfheide (2015). Bayesian estimation of DSGE models. Princeton University Press.

Koop, G., M. H. Pesaran, and S. M. Potter (1996). Impulse response analysis in nonlinear multivariate models. Journal of econometrics $74(1), 119-147$.

Leeper, E. M., T. B. Walker, and S.-C. S. Yang (2013). Fiscal foresight and information flows. Econometrica $81(3), 1115-1145$.

Nelson, R. M., P. Belkin, and D. E. Mix (2011). Greece's debt crisis: overview, policy responses and implications. Journal of Current Issues in Finance, Business and Economics 4 (4), 371.

Reinhart, C. M. and K. S. Rogoff (2009). This time is different: Eight centuries of financial folly. princeton university press.

Tauchen, G. and R. Hussey (1991). Quadrature-based methods for obtaining approximate solutions to nonlinear asset pricing models. Econometrica: Journal of the Econometric Society, 371-396. 


\section{Appendix}

\section{A The Two-Period Model}

This section shows the proof of propositions in the two-period model.

\section{A.1 Proof of proposition 1:}

Proof. We solve for the optimal tax rate backward, given the government default decision $d$, debt balance $b_{2}$, and income realization $y_{2}$. Therefore, the government sets the tax rate $\tau$ to maximize the household's utility in the second period:

$$
\max _{\tau}(1-\pi) \frac{c_{2}^{1-\sigma}}{1-\sigma}+\pi \frac{g_{2}^{1-\sigma}}{1-\sigma}
$$

subject to the second-period private and public consumption as specified in equations (4) and (5). Therefore, the government's optimal tax policy, contingent on the government's default decision, can be solved analytically:

$$
\begin{aligned}
\tau^{* R}\left(b_{2}, y_{2}\right) & =\frac{\pi^{\frac{1}{\sigma}}+(1-\pi)^{\frac{1}{\sigma}} \frac{b_{2}}{y_{2}}}{\pi^{\frac{1}{\sigma}}+(1-\pi)^{\frac{1}{\sigma}}}, \quad b_{2}<y_{2} \\
\tau^{* D} & =\frac{\pi^{\frac{1}{\sigma}}}{\pi^{\frac{1}{\sigma}}+(1-\pi)^{\frac{1}{\sigma}}},
\end{aligned}
$$

Therefore, we can easily see that the proposition 1 holds.

\section{A.2 Proof of proposition 2:}

Proof. Given the optimal tax policy, we have the period 2 value function of repaying and defaulting governments:

$$
\begin{aligned}
& V^{2, R}\left(y_{2}, b_{2}\right)=\left[\pi^{\frac{1}{\sigma}}+(1-\pi)^{\frac{1}{\sigma}}\right]^{\sigma} \frac{\left(y_{2}-b_{2}\right)^{1-\sigma}}{1-\sigma} \\
& V^{2, D}\left(y_{2}\right)=\left[\pi^{\frac{1}{\sigma}}+(1-\pi)^{\frac{1}{\sigma}}\right]^{\sigma} \frac{\left(\phi y_{2}\right)^{1-\sigma}}{1-\sigma}
\end{aligned}
$$

By comparing the values of repay and default, we may find that the government defaults on its debt only when $y_{2}<\frac{b_{2}}{1-\phi}$.

\section{A.3 Proof of proposition 3}

Proof. Given the commitment tax rate $\tau$, the value of repay and default can be written as:

$$
V^{R}\left(y_{2}, b_{2}, \tau\right)=(1-\pi) \frac{\left[(1-\tau) y_{2}\right]^{1-\sigma}}{1-\sigma}+\pi \frac{\left(\tau y_{2}-b_{2}\right)^{1-\sigma}}{1-\sigma}
$$




$$
V^{D}\left(y_{2}, \tau\right)=(1-\pi) \frac{\left[(1-\tau) \phi y_{2}\right]^{1-\sigma}}{1-\sigma}+\pi \frac{\left(\tau \phi y_{2}\right)^{1-\sigma}}{1-\sigma}
$$

So, the default region is characterized by:

$$
\mathbb{D}\left(b_{2}, \tau\right)=\left\{y_{2} \in\left[y_{\text {min }}, y_{\text {max }}\right] \mid V^{R}\left(y_{2}, b_{2}, \tau\right)<V^{D}\left(y_{2}, \tau\right)\right\}
$$

Specifically, the optimal default decision is characterized by default threshold that depends on debt balance and tax rate chosen in period 1 ,

$$
\bar{y}_{2}\left(b_{2}, \tau\right)=\frac{b_{2}}{\tau-\left[(\tau \phi)^{1-\sigma}-\left(1-\phi^{1-\sigma}\right) \frac{1-\pi}{\pi}(1-\tau)^{1-\sigma}\right]^{\frac{1}{1-\sigma}}}
$$

It is easy to show $\frac{\partial \bar{y}_{2}\left(b_{2}, \tau\right)}{\partial \tau}<0$ and $\frac{\partial \bar{y}_{2}\left(b_{2}, \tau\right)}{\partial b}>0$ under relevant parameter values.

\section{B Specification of the State-Space Model}

To estimate the variables and shock realizations, we map our model into the Greek data using bootstrapped particle filter. Let $\mathbb{Y}_{t}=\left[G D P_{t}, G_{t}\right]^{\prime}$ be the vector of the data observables which consists of the quarterly detrended GDP and government consumption during 1997 Q3 to 2017 Q3. $\mathbb{S}_{t}$ denotes the state vector of the model:

$$
\mathbb{S}_{t}=\left[z_{t}, y_{t}, g_{t}, c_{t}, l_{t}, \tau_{t}, \operatorname{spr}_{t}\right]^{\prime}
$$

Then, the state-space form of the model can be represented by:

$$
\begin{aligned}
& \mathbb{S}_{t}=\Phi\left(\mathbb{S}_{t-1}, \epsilon_{t}^{z}\right) \\
& \mathbb{Y}_{t}=\Psi\left(\mathbb{S}_{t}\right)+u_{t}
\end{aligned}
$$

The first one is the transitional equation coming from the numerical solution of the model. The second one is the measurement equation that relates our model variables to the data counterparts. Since this is a numerical filter and we do not want the likelihood function to degenerate, we introduce the 2-by-1 measurement error $u_{t}=\left[u_{t}^{G D P}, u_{t}^{G}\right]^{\prime}$ which follows an i.i.d. process. Notice that the model only has one structural shock but it is used to match two paths of data observations. That creates extra challenges for us to have a good model fitting performance. In addition, our paper provides a sovereign default model with an optimal government spending policy. But in reality, the change in the government spending is partly accounted by shocks that makes the observations deviate from the optimal policy. On the other hand, the systematic fiscal rules in advanced countries also introduce a sluggish movement of government spending which cannot be described by the incentives in this paper. To account for these misspecifications, we impose a relatively higher measurement error standard deviation on government consumption than that of 
GDP. Specifically, the covarince matrix of measurement error is given by

$$
\operatorname{var}\left(u_{t}\right)=\Sigma_{t}^{u}=\left[\begin{array}{cc}
{[5 \% \times \operatorname{std}(G D P)]^{2}} & 0 \\
0 & {[50 \% \times \operatorname{std}(G)]^{2}}
\end{array}\right]
$$

The steps of particle filter follows Herbst and Schorfheide (2015).

One thing to notice is that the interest rate spread (or bond price) is not defined when the model goes to default states. But in reality, we have seen even after Greece defaulted on its debt in 2012 and 2015, the Greek government bonds were still traded and there was still risk premium data. In our simulation, we exclude those particles under financial exclusion when the spreads or bond prices are calculated. Therefore, this model misspecification creates a downward bias on the estimation of spreads and could partly explain the difference between the spread series in the data and the model. However, the comparison of different fiscal policy commitment is not affected by this misspecification.

After we estimate the case 1 model (discretionary policy), we extract a series of productivity shocks $\left\{\hat{z}_{t}\right\}_{t=1997 Q 3}^{2017 Q 3}$ and the estimated state variables $\left\{\hat{\mathbb{S}}_{t}\right\}_{t=1997 Q 3}^{2017 Q 3}$. Taking the 2009Q4 as the initial state, we feed in all the extracted path of shocks after that date to the model under case 2 and case 3. The state-space form for these two models are similar to B.11, B.12. The counterfactual exercise compares the model-predicted spreads in the baseline economy (under discretionary policy) with the economies under fiscal commitment.

\section{Computational Details and Algorithm for Case 3}

The full model is solved by value function iteration and linear interpolation. Specifically, we discretize the debt state and approximate the value functions $V^{R}, V^{D}$ and the bond price $q$ by linear functions. We iterate the recursive functional equations defined in the main text and stop when the distance between the value functions and bond prices in successive iterations is small enough. The expectations are evaluated using the method in Tauchen and Hussey (1991).

The economic problem in the case of contingent tax commitment (case 3) is more complicated, since the commitment device itself is a functional object. As defined in the paper, in each period the government chooses a schedule of tax rates $\mathfrak{t}^{\prime} \in \mathfrak{T}$ that will be implemented in the next period. In the full model, the realized tax rate at each state can only take two values: $\tau^{L}$ or $\tau^{H}$. In this section, we show this assumption simplifies our algorithm and makes our computation feasible for case 3.

First, for each level of debt issuance $b^{\prime}$, the government chooses a tax rate schedule $\mathfrak{t}^{\prime} \in \mathfrak{T}$. If $Z$ space has $\mathrm{N}$ number of grids points, then that means the government jointly chooses $\mathrm{N}$ number of tax rates from either $\tau^{H}$ or $\tau^{L}$. Next, we show this selection problem can be reduced to simply choosing a threshold on $Z$, above which the government sticks to the high tax rate $\tau^{H}$, under certain conditions. And we argue these conditions are not restrictive and are easy to be satisfied. The first assumption states that when the level of productivity increases, the net benefit of repaying the debt over defaulting on it also increases. This assumption is natural, since most default models 
use an increasing default cost function to account for the counter-cyclical default risk seen in the data.

Assumption 1. For any value of tax rate in the next period: $\tau^{\prime}=\tau^{H}$ or $\tau^{\prime}=\tau^{L}$, and for any level of borrowing $b^{\prime}$, the function $V^{R}\left(b^{\prime}, \tau^{\prime}, z^{\prime}\right)-V^{D}\left(\tau^{\prime}, z^{\prime}\right)$ is increasing in $z^{\prime}$ if both functions are well-defined.

The following assumption extends that to the case when the tax rate under repayment is different from the tax rate under default.

Assumption 2. For any level of borrowing $b^{\prime}$, the function $V^{R}\left(b^{\prime}, \tau^{H}, z^{\prime}\right)-V^{D}\left(\tau^{L}, z^{\prime}\right)$ (and $\left.V^{R}\left(b^{\prime}, \tau^{L}, z^{\prime}\right)-V^{D}\left(\tau^{H}, z^{\prime}\right)\right)$ is also increasing in $z^{\prime}$ if both functions are well-defined.

This assumption points out that the positive effect of the productivity on the government's repayment incentive still holds when the tax rates are different between repayment and default, as long as those tax rates are constant. The next assumption considers the effect of an increase in the tax rate.

Assumption 3. If $\tau^{L}<\tau^{H}$, a higher tax rate increases the net benefit of repaying the debt:

$$
V^{R}\left(b^{\prime}, \tau^{L}, z^{\prime}\right)-V^{D}\left(\tau^{L}, z^{\prime}\right) \leq V^{R}\left(b^{\prime}, \tau^{H}, z^{\prime}\right)-V^{D}\left(\tau^{H}, z^{\prime}\right)
$$

for every given $z^{\prime}$ and $b^{\prime}$ if all functions are well-defined.

This assumption extends the proposition 3 of the two-period model and states that a higher tax rate makes repaying the debt relatively easier. In the full model, this channel is especially relevant when the bond risk premium rises up so that the government finds it difficult to roll-over the debt and the higher tax rate helps it relieve the debt burden. We can also see this assumption is reasonable from the case 2 economy that the default probability is decreasing as the preset tax rate gets higher. The above assumptions help us identify two default thresholds under the two tax rates.

Corollary 4. Under assumption 1 and 3, we can conclude that the default threshold (on the $Z$ space) associated with the high tax rate is weakly lower than the default threshold of the low tax rate:

$$
z^{*}\left(b^{\prime}, \tau^{H}\right) \leq z^{*}\left(b^{\prime}, \tau^{L}\right)
$$

Proof. The case is trivial if the government is certain to repay or default and the default thresholds goes to either ending points of $Z$. Suppose both default thresholds are interior: $z^{*}\left(b^{\prime}, \tau^{H}\right) \in$ $\left(z_{\min }, z_{\max }\right)$ and $z^{*}\left(b^{\prime}, \tau^{L}\right) \in\left(z_{\min }, z_{\max }\right)$.

By definition, at $z^{*}\left(b^{\prime}, \tau^{L}\right)$, the value of repayment and the value of default are equalized when the tax rate is low: $V^{R}\left(b^{\prime}, \tau^{L}, z^{*}\left(b^{\prime}, \tau^{L}\right)\right)-V^{D}\left(\tau^{L}, z^{*}\left(b^{\prime}, \tau^{L}\right)\right)=0$. By assumption $3, V^{R}-V^{R}$ is consistently higher under $\tau^{H}$ than under $\tau^{L}$ for each $b^{\prime}$ and all $z^{\prime}$. So, $V^{R}\left(b^{\prime}, \tau^{H}, z^{*}\left(b^{\prime}, \tau^{L}\right)\right)-$ $V^{D}\left(\tau^{H}, z^{*}\left(b^{\prime}, \tau^{L}\right)\right) \geq 0$. Then, by assumption 1 , the $V^{R}-V^{D}$ is an increasing function of $z^{\prime}$ for each value of tax rate. If the point crossing horizontal axis $\left(z^{*}\left(b^{\prime}, \tau^{H}\right)\right)$ exists, it must be on the left side of $z^{*}\left(b^{\prime}, \tau^{L}\right)$. Given we have supposed the solution is interior, we have $z^{*}\left(b^{\prime}, \tau^{H}\right) \leq z^{*}\left(b^{\prime}, \tau^{L}\right)$. 


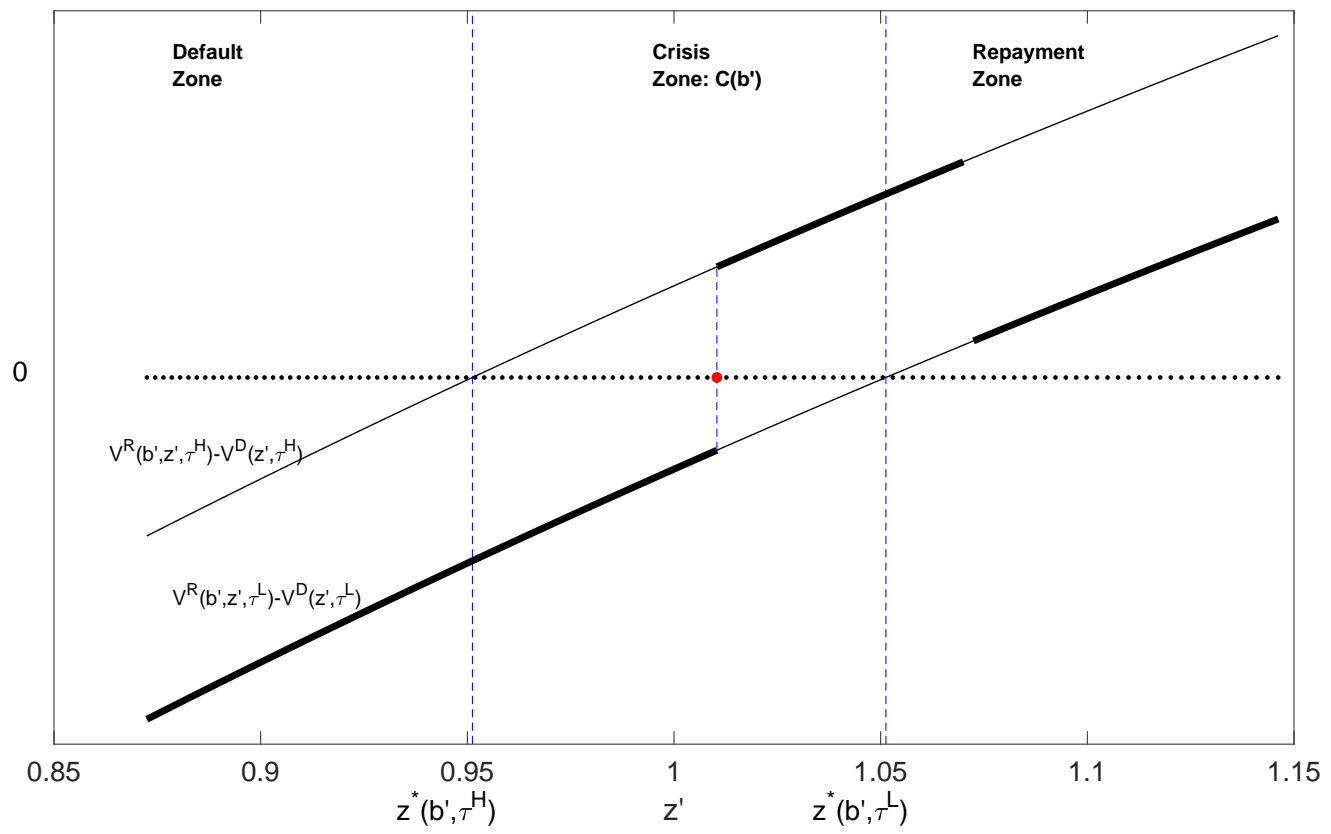

Note: The figure plot $V^{R}-V^{D}$ as a function of $z^{\prime}$ for the high and low tax rate. The thick part of lines indicate the government's contingent tax rate choices for each value of $z^{\prime}$. The red dot indicates the default threshold under the optimal contingent tax commitment.

Figure C.1: The relative benefit of repayment over default

Given corollary 4, we can cut the state space of $Z$ into three areas for every intended level of bond issuance $b^{\prime}$. To the right of $z^{*}\left(b^{\prime}, \tau^{L}\right)$, the government always repays, no matter what tax rate it faces. We call it Repayment Zone: $\mathcal{R}\left(b^{\prime}\right)$. To the left of $z^{*}\left(b^{\prime}, \tau^{H}\right)$, the government will default on its debt, independent of the tax rate. We call it Default Zone: $\mathcal{D}\left(b^{\prime}\right)$. In the middle area, whether the government chooses to default or repay depends on the committed tax rate. This region is called Crisis Zone: $\mathcal{C}\left(b^{\prime}\right)$. Figure C.1 plots the functions of $V^{R}-V^{D}$ under the two tax rates and describe these zones.

If the next period productivity lies in the repayment zone, the government will repay no matter what the tax rate is. The current government expect that and let the next period government to choose its tax rate discretionarily. The tax rate is determined by comparing the repayment value with the default value $\tau^{\prime}=\operatorname{argmax}\left\{V^{R}\left(b^{\prime}, z^{\prime}, \tau^{H}\right), V^{R}\left(b^{\prime}, z^{\prime}, \tau^{L}\right)\right\}$. The same is true for the points in the default zone and the tax is determined by: $\tau^{\prime}=\operatorname{argmax}\left\{V^{D}\left(z^{\prime}, \tau^{H}\right), V^{D}\left(z^{\prime}, \tau^{L}\right)\right\}$. However, when $z^{\prime} \in \mathcal{C}\left(b^{\prime}\right)$, the tax rate has an effect on default decisions and all the tax rates across crisis zone are chosen jointly. The following assumption simplifies our analysis.

Assumption 4. Denote $\mathbb{P}\left(z^{\prime} \mid z\right)$ as the transitional density of the Markov process. Let $z$ be the current productivity state. Assume for $\forall z^{\prime} \in \mathcal{C}\left(b^{\prime}\right), \mathbb{P}\left(z^{\prime} \mid z\right)$ is increasing in $z^{\prime}$.

The assumption 4 means that given current $z$, the crisis region in the next period belongs to the low productivity area so that a point to the right in the crisis region always has the greater likelihood than a point to the left. Intuitively, this is reasonable since we find in equilibrium the 
government can never borrow at a very high interest rate spread (or very low bond price). That is, the crisis zone lies in the far left tail of the conditional distribution of $z^{\prime}$ given $z$.

Given this assumption, we are able to characterize the contingent tax commitment problem by choosing a threshold in the crisis zone. We first characterize the optimal tax and default problem under a discretionary fiscal policy.

Corollary 5. Under assumptions 1, 2, 3, and assume that the governments use a discretionary tax policy, then we have the following:

1. If the governments will repay at a certain point $z_{1}^{\prime} \in \mathcal{C}\left(b^{\prime}\right)$, then they will also repay at any point $z_{2}^{\prime}$ that satisfies $z_{2}^{\prime} \in \mathcal{C}\left(b^{\prime}\right)$ and $z_{2}^{\prime}>z_{1}^{\prime}$;

2. If the governments will default at a certain point $z_{1}^{\prime} \in \mathcal{C}\left(b^{\prime}\right)$, then they will also default at any point $z_{2}^{\prime}$ that satisfies $z_{2}^{\prime} \in \mathcal{C}\left(b^{\prime}\right)$ and $z_{2}^{\prime}<z_{1}^{\prime}$.

Proof. Suppose $z_{1}^{\prime}, z_{2}^{\prime} \in \mathcal{C}\left(b^{\prime}\right)$ and $z_{2}^{\prime}>z_{1}^{\prime}$. When making default or repayment decisions, the discretionary government only consider the contemporary values of repayment and default (in the next period). Because both points are in the crisis zone, the government optimally chooses $\tau^{H}$ when it repays and chooses $\tau^{L}$ when it defaults. Since the government repays at $z_{1}^{\prime}$, we have $V^{R}\left(b^{\prime}, z_{1}^{\prime}, \tau^{H}\right) \geq V^{D}\left(z_{1}^{\prime}, \tau^{L}\right)$. From assumption 3, the $V^{R}\left(b, z^{\prime}, \tau^{H}\right)-V^{D}\left(z^{\prime}, \tau^{L}\right)$ is increasing in $z^{\prime}$. So, at point $z_{2}^{\prime}$, we also have $V^{R}\left(b^{\prime}, z_{2}^{\prime}, \tau^{H}\right) \geq V^{D}\left(z_{2}^{\prime}, \tau^{H}\right)$. Therefore, the government prefers to repay the debt rather than defaults on it at $z_{2}^{\prime}$.

The proof of the second part of the corollary is similar to the first part.

Corollary 5 implies that the government's default decision in case 1 is characterized by a threshold in the crisis zone, which is denoted by $\tilde{z}^{c 1}\left(b^{\prime}\right) \in \mathcal{C}\left(b^{\prime}\right)$. More importantly, for any points in the crisis zone above (below) the threshold, the government would like to choose the high (low) tax rate $\tau^{H}$ $\left(\tau^{L}\right)$. The following corollary says this is also true for the government in case 3 .

Corollary 6. Under assumption 1, 2, 3, 4, and assume that the governments can commit to a contingent tax policy, then we have:

1. If the governments will repay at a certain point $z_{1}^{\prime} \in \mathcal{C}\left(b^{\prime}\right)$, then they will also repay at any point $z_{2}^{\prime}$ that satisfies $z_{2}^{\prime} \in \mathcal{C}\left(b^{\prime}\right)$ and $z_{2}^{\prime}>z_{1}^{\prime}$;

2. If the governments will default at a certain point $z_{1}^{\prime} \in \mathcal{C}\left(b^{\prime}\right)$, then they will also default at any point $z_{2}^{\prime}$ that satisfies $z_{2}^{\prime} \in \mathcal{C}\left(b^{\prime}\right)$ and $z_{2}^{\prime}<z_{1}^{\prime}$.

Proof. The logic of the proof is similar to that in corollary 5, except that now the government with tax commitment internalizes the ex ante effect of its default decision on the current bond price.

Holding everything else equal, if the government will repay at the point $z_{1}^{\prime}$ in the next period, it attains a current value of

$$
\tilde{V}^{R}\left(z_{1}^{\prime}\right)=\frac{\left(g^{*}+b^{\prime} \mathbb{P}\left(z_{1}^{\prime} \mid z\right) /(1+r *)\right)^{1-\sigma}}{1-\sigma}+\beta V^{R}\left(b^{\prime}, z_{1}^{\prime}, \tau^{H}\right)+u\left(c^{*}, l^{*}\right)+\beta \mathbb{E}_{z^{\prime} \neq z_{1}^{\prime}}\left(V^{\prime}\right)
$$




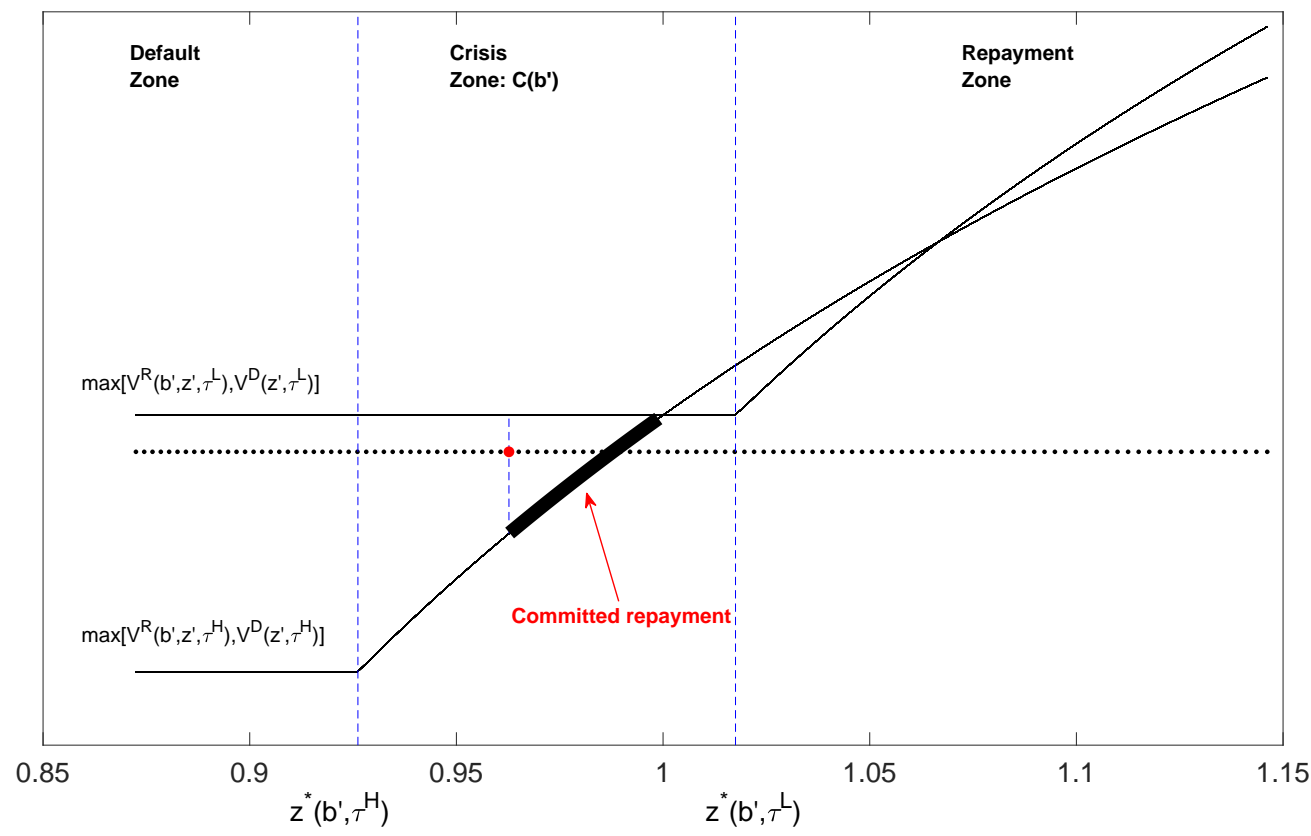

Note: The figure plots $\max \left[V^{R}, V^{D}\right]$ as a function of $z^{\prime}$ for the high and low tax rate. The thick part are the committed repayment points: the government will choose to repay only because it uses the high tax rate commitment. The red dot indicates the optimal default threshold for the government in case 3.

Figure C.2: The next period value functions

If the government defaults on the debt at $z_{1}^{\prime}$ in the next period, it gets:

$$
\tilde{V}^{D}\left(z_{1}^{\prime}\right)=\frac{\left(g^{*}\right)^{1-\sigma}}{1-\sigma}+\beta V^{D}\left(z_{1}^{\prime}, \tau^{L}\right)+u\left(c^{*}, l^{*}\right)+\beta \mathbb{E}_{z^{\prime} \neq z_{1}^{\prime}}\left(V^{\prime}\right)
$$

The last two terms do not depend on the default decision at $z_{1}^{\prime}$. So, the net marginal value of repayment at $z_{1}^{\prime}$ is proportional to $\mathbb{P}\left(z_{1}^{\prime} \mid z\right)$ and $V^{R}\left(b^{\prime}, z_{1}^{\prime}, \tau^{H}\right)-V^{D}\left(z_{1}^{\prime}, \tau^{L}\right)$. By assumption 4 , the conditional probability is increasing in $z^{\prime}$ for the given state $z$. So, for $z_{2}^{\prime}>z_{1}^{\prime}$, we have $\mathbb{P}\left(z_{2}^{\prime} \mid z\right)>\mathbb{P}\left(z_{1}^{\prime} \mid z\right)$. On the other hand, by assumption 3 , we have $V^{R}\left(b^{\prime}, z_{2}^{\prime}, \tau^{H}\right)-V^{D}\left(z_{2}^{\prime}, \tau^{L}\right)>$ $V^{R}\left(b^{\prime}, z_{1}^{\prime}, \tau^{H}\right)-V^{D}\left(z_{1}^{\prime}, \tau^{L}\right)$. Overall, we have

$$
\tilde{V}^{R}\left(z_{2}^{\prime}\right)-\tilde{V}^{D}\left(z_{2}^{\prime}\right)>\tilde{V}^{R}\left(z_{1}^{\prime}\right)-\tilde{V}^{D}\left(z_{1}^{\prime}\right)
$$

That means the net benefit of repaying the debt over default is even larger at a higher productivity point $z_{2}^{\prime}$ than at $z_{1}^{\prime}$. Since the government commit to repay at $z_{1}^{\prime}$, it also would like to commit to repay at $z_{2}^{\prime}$.

The proof of the second part of the corollary is similar to the first part.

The corollary implies that the default decision under contingent tax commitment is also characterized by a threshold in the crisis zone. This threshold is denoted by $\tilde{z}^{c 3}\left(b^{\prime}\right) \in \mathcal{C}\left(b^{\prime}\right)$. We can see from the proofs, compared to the discretionary policy, the net benefit of repaying is larger in the case of contingent commitment. This moves the default threshold to the left. That means the 
default threshold under case 3 must be not higher than the threshold in case 1 .

$$
\tilde{z}^{c 3}\left(b^{\prime}\right) \leq \tilde{z}^{c 1}\left(b^{\prime}\right)
$$

Figure C.2 shows the next period value functions under the high and low tax rates. First of all, the high tax rate pushes down the default threshold and opens the window of crisis zone. Second, the government will repay at certain points in the crisis zone where the value of repayment (taxing at $\tau^{H}$ ) goes below the value of default (taxing at $\tau^{L}$ ). Those points only appears because the government incorporates the commitment's effect on the bond price. I call the points Committed Repayment.

After we have shown the commitment device expands the repayment area, we propose the tax rates structure that the current government plans to choose in the following period.

Corollary 7. Under assumption 1, 2, 3, 4, the committed tax schedule is a piece-wise function for every given $b^{\prime}$ :

$$
\mathfrak{t}^{\prime}\left[z^{\prime}\right]=\left\{\begin{array}{cl}
\operatorname{argmax}\left\{V^{D}\left(z^{\prime}, \tau^{H}\right), V^{D}\left(z^{\prime}, \tau^{L}\right)\right\}, & \text { if } z_{\min } \leq z^{\prime} \leq z^{*}\left(b^{\prime}, \tau^{H}\right) ; \\
\tau^{L}, & \text { if } z^{*}\left(b^{\prime}, \tau^{H}\right)<z^{\prime} \leq \tilde{z}^{c 3}\left(b^{\prime}\right) ; \\
\tau^{H}, & \text { if } \tilde{z}^{c 3}\left(b^{\prime}\right)<z^{\prime} \leq z^{*}\left(b^{\prime}, \tau^{L}\right) ; \\
\operatorname{argmax}\left\{V^{R}\left(b^{\prime}, z^{\prime}, \tau^{H}\right), V^{R}\left(b^{\prime}, z^{\prime}, \tau^{L}\right)\right\}, & \text { if } z^{*}\left(b^{\prime}, \tau^{L}\right)<z^{\prime} \leq z_{\max } .
\end{array}\right.
$$

Proof. Notice that in the crisis zone, the government will choose the high tax (low) rate at the same time when it chooses to repay (default). Everything else is trivial given the corollary 4, 5, 6, and 7 .

By these assumptions and corollaries, the government's tax commitment choice in case 3 is numerically feasible. In each period, the current government is choosing the bond issuance $b^{\prime}$ and tax schedule $\mathfrak{t}^{\prime}\left[z^{\prime}\right]$ simultaneously. By corollary 7 , choosing $\mathfrak{t}^{\prime}\left[z^{\prime}\right]$ is equivalent to choosing a threshold grid point in $\mathcal{C}\left(b^{\prime}\right)$. In our algorithm, given the functions from the last iteration, the crisis zone $\mathcal{C}\left(b^{\prime}\right)$ can be precomputed for each level of $b^{\prime}$ and we search for $z^{\prime} \in \mathcal{C}\left(b^{\prime}\right)$ to maximize the current value function. After the code converges, we also confirmed all the above assumptions are numerically satisfied.

In equilibrium, we find the government indeed uses the high tax rate commitment at certain state $(b, \tau, z)$, as in the two-period model. That means the committed repayment area in figure C.2 is not empty. That explains the figure 7 that the contingent tax commitment successfully reduces the default incentives and improves the bond price.

\section{Model with the Higher Risk Aversion}

In section 4.5, we solve the model again with a higher risk aversion parameter on the public consumption: $\sigma_{g}=3$ while keep the parameters from the literature unchanged (same as in table 2 ). Then we recalibrate the model under discretionary fiscal policy to the Greek economy and the 
new parameters are listed in table D.1. The model moments under the new parameter values are shown in table D.2.

\begin{tabular}{lcc} 
Description & Parameters & Value \\
\hline \hline Discount factor & $\beta$ & 0.88 \\
Fixed default cost & $d_{0}$ & -1.082 \\
Proportional default cost & $d_{1}$ & 1.167 \\
TFP innovation size & $\sigma_{z}$ & 0.0138 \\
\hline
\end{tabular}

Table D.1: Parameter Values for the Model with $\sigma_{g}=3$

\begin{tabular}{lccc} 
& Data & $\begin{array}{c}\text { Baseline } \\
\text { Calibration }\end{array}$ & $\begin{array}{c}\text { High } \\
\text { Risk Aversion }\end{array}$ \\
\hline \hline Targeted Moments: & & & \\
Debt service-output & $5.43 \%$ & $5.20 \%$ & $5.18 \%$ \\
Average spread & $4.45 \%$ & $4.17 \%$ & $3.92 \%$ \\
Standard deviation of spread & $5.49 \%$ & $7.51 \%$ & $7.65 \%$ \\
Standard deviation of output & 12.53 & $11.76 \%$ & 11.27 \\
\hline Other Statistics: & & & \\
Default probability & $2.80 \%$ & $3.40 \%$ & $3.08 \%$ \\
std $(\mathrm{g}) /$ std $(y)$ & 0.94 & $1.08 \%$ & 1.35 \\
\hline
\end{tabular}

Table D.2: Model Moments for the Model with $\sigma_{g}=3$

\section{E Additional Figures}

Figure E.3 shows the additional policy functions in our full model and we compare the three cases. Case 1 is the discretionary fiscal policy. Case 2 is the fiscal policy under non-contingent commitment. Case 3 is the fiscal policy under non-contingent commitment. Figure E. 4 shows the long-run statistics in the models with different values of austerity tax rate: $\tau^{H}$. 

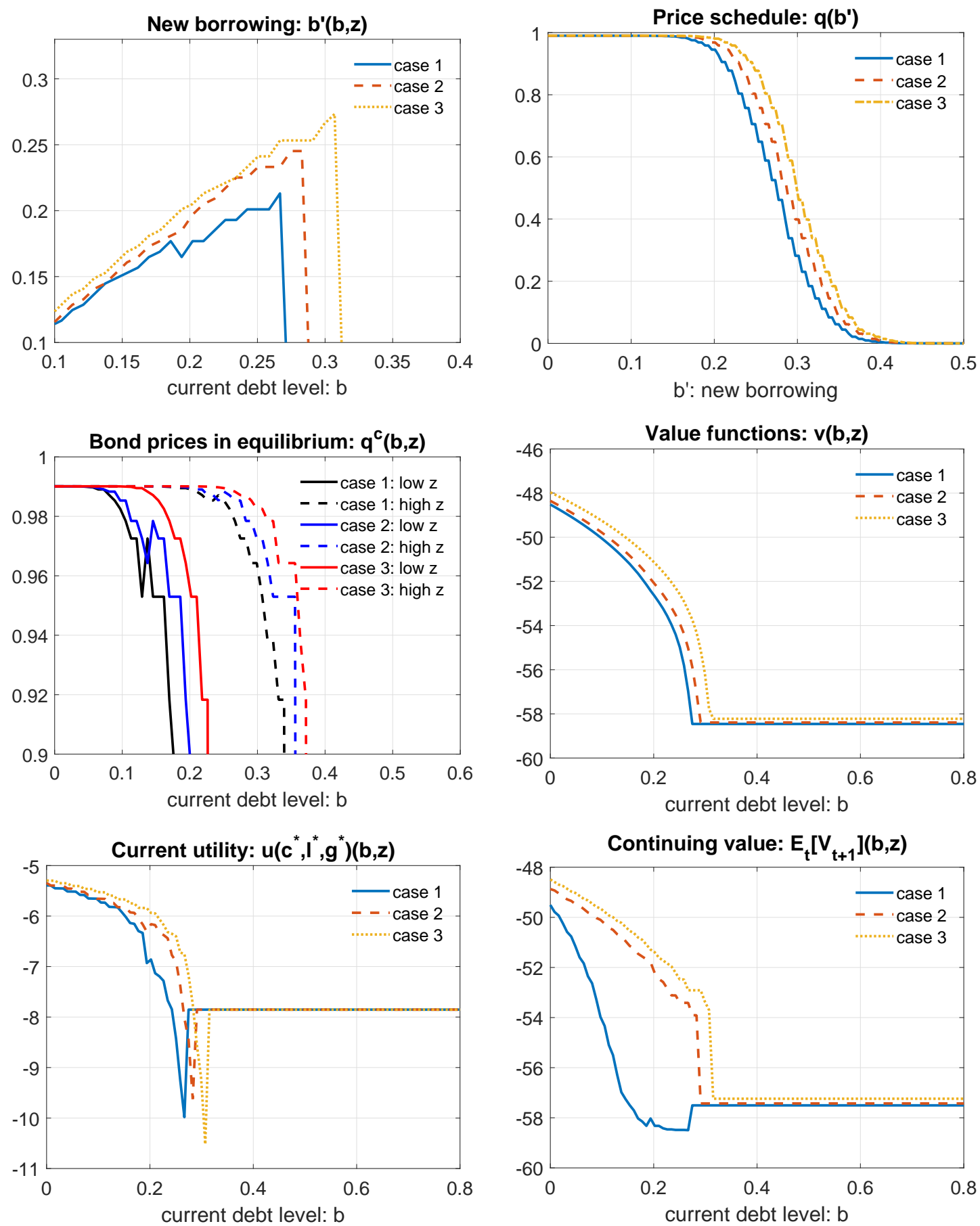

Note: The figures plot the policy functions for case 1 (discretionary fiscal policy, solid lines), case 2 (non-contingent tax commitment, dashed lines), and case 3 (contingent tax commitment, dotted lines). The current productivity is set to its mean. In case 2 and case 3 , the current tax rate is set at $\tau^{L}$. To compare the bond prices, we dissect the choice problem in case 2 and case 3 so that for each level of $b^{\prime}$, the government optimally set the committed tax rate (case 2) or tax schedule (case 3) for the next period. In the middle left figure, the high (low) productivity is set at one standard deviation above (below) the mean.

Figure E.3: Other Policy Rules about Tax Commitment 

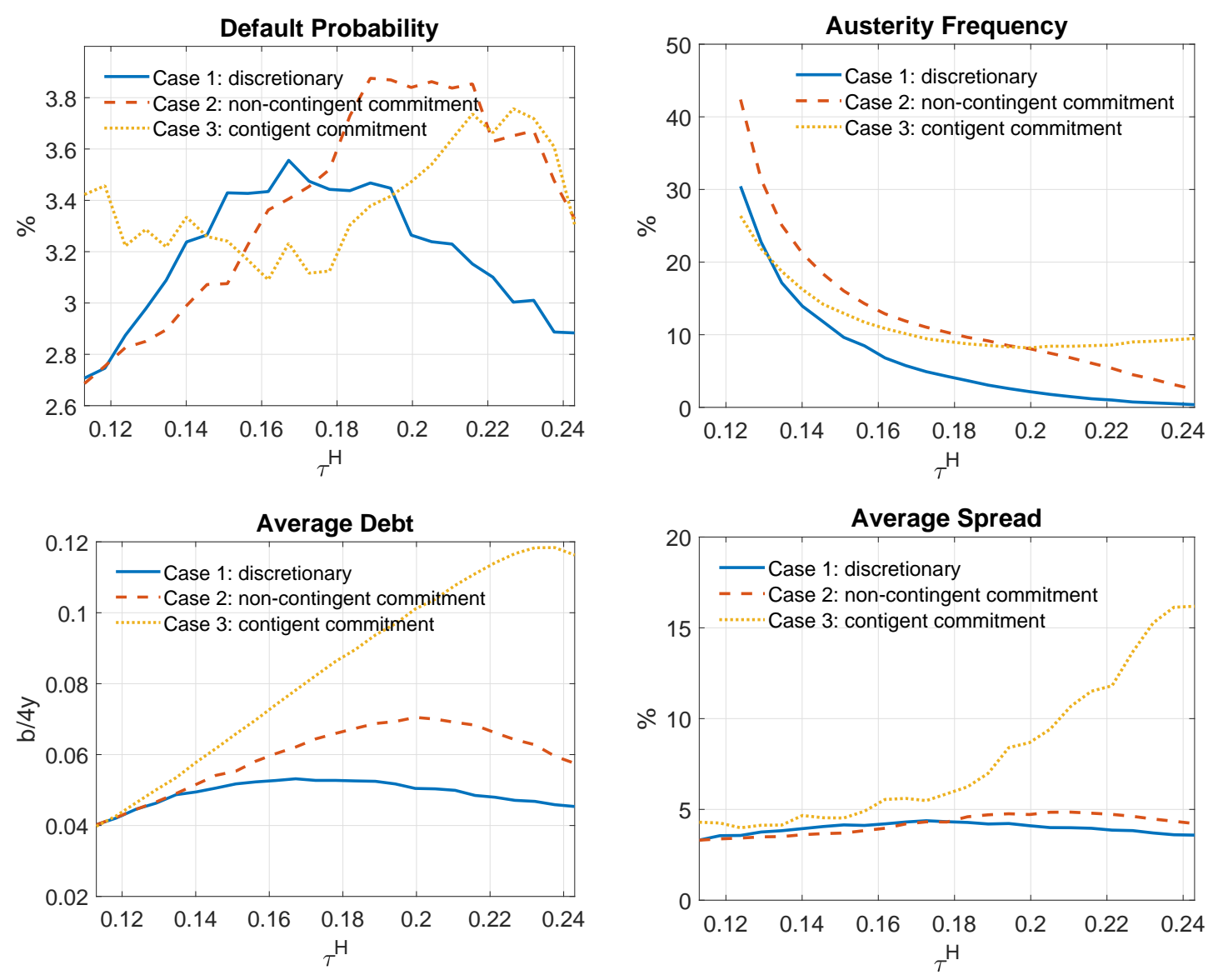

Note: For each value of $\tau^{H}$, we solve the three models and simulate each economy over a long period of time. The average debt and spread are the averaged values during the event window defined under table 3 .

Figure E.4: Varying the Size of Austerity: Default Probability, Austerity Frequency, Debt Ratio, Spread 